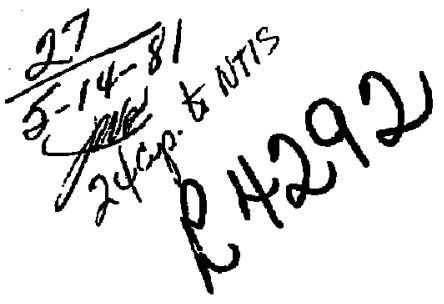

\title{
A COMPUTATIONAL COMPACT TORUS EXPERIMENT
}

\section{J. L. Eddlenan}

B. McNamara

J. K. Nash

J. W. Shearer

w. C. Turner

This is an informal report iatended primnily for internal or liaited exteral distribotion. The oplabas and condusions stified are those of the actbor and any or miny eot be those of the LAbortitory.

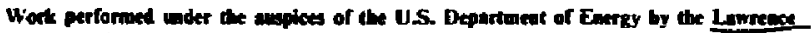

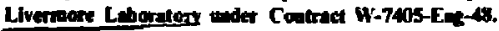

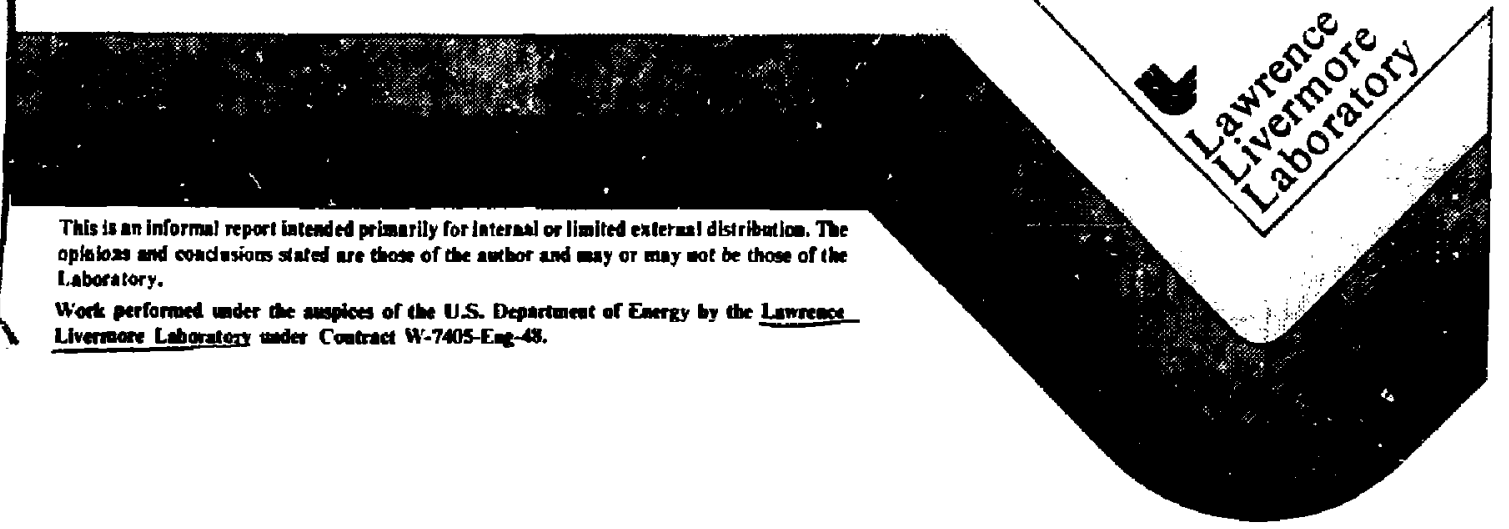




\section{A COMPUTATIONAL COMPACT TORUS EXPERIMENT}

ABSTRACT

We describe a typical 2D magnetohydrodynamic (MHD) calculation of rundown of plasma in a coaxial, magnetized gun and injection of the plasma and raconnection of the embedded magnetic fields to form a compact toroidal plasma.

\section{INTRODUCTION}

The two-dimensional $(r, z, t)$ magnetohydrodynamic code, HAM, has been used to model the performance of the magnetized, coaxial plassa gun injecting a plasma ring into a copper flux cunserving chamber, as used in the Beta-IT experiment. 2,3 The inclusion of all the experimental hardware in the calculation makes it very lengthy, but it gives a wealth of information and insigit into every aspect of the experiment-breakdown, production of the gun plasma, field-line reconnection, and formation of a cotpact toroid. We will display these results with some brief interpretations. The calculatious will lead to simpler, more furdamental studies to elucidate different pieces of the physical processes involved. The qualitative results of the calculations appear correct, but a quantitative calibration of the numerical against the laboratory experiment remains to be done. Two principal defects are immediately evident in the laboratory: the code has no model of the desorption of gas or the sputtering of impurities frow the gun, and these appear to be important in creating energy losses from the plasma and enhancing the resistivity. The impurity input depends upon the current density and the plesma temperature, which sputters material locally or desorbs other gases from the electrodes, and upon the total plasma-wall contact time. Evidently, numerical experiments could be performed to improve future gun designs along this line. The second defect of the simulation is that, being axisymetric, it is unable to model MHD instabilities. Stability catculations by Dalhed ${ }^{4}$ and laboratory results show that the guide field of 500 gauss (G) used here would lead to rapid-tilting instability after the toroid is formed. Future simulations can avoid this by keeping the guide field below Dalhed's estimate of the maximum, which, in this geometry, is $B_{G}(k G)<1.6 I_{\theta}(M A)$. The total toroidal current is $I_{\theta}$.

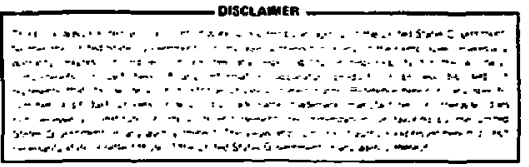


Most of this report simply presents the computational results with rather brief explanations. Some of the more important observations are as follows:

1. The gun produces two plasmas, a very dense one pressed radially outwards on the anode, and a lorver density plaswa around the cathode which accelerates ahead of the dense plasma to become the compact toroid. The dense plasma never really separates from the gun and falis back into it at the end of the discharge. Laboratory diagnostics are not yet sufficient to determine if this is correct.

2. The field-line reconnection seems to be affected by plasma flow through the gap between the gun and the flux conserver (see Fig. 1) and even more by plasna flow inco the expansion region of the flux conserver.

3. The plasma resistivity is anomalous in the reconnection regions,

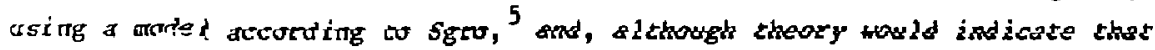
the reconnection rate should be independent of resistivity, ${ }^{6}$ this point needs to be confirmed in more elementary simulations.

4. The efficiency of converting the capacitor bank energy into plasma and aagnetic energ. trapped in the toroid is only a few percent. This could be improved hy varying the power input to the gun and exercising better control over the reconnection process. The parameters of the laboratory experiment will be varied to improve this.

5. The current and voltage variations have considerable effects on the rinal toroid produced, which needs to be understood in terms of some simpler model. The laboratory gun crowbars the applied voltage at the peak current, an effect not described here.

6. The laboratory experiment comes to equilibrium with about double the poloidal flux proyided by the gun embedied in the campact torus. This 'flux amplitication' is a three-dimensional effect of reconnection of large-amplitude helical instabilities and is qualitatively explained by evaluating the minimum-energy final state ...ith the initial total magnetic helicity provided $\dot{0}_{y} ;$ the gun currents.

\section{INITIAL CONDITIONS}

The geometry and dimensions of the problem are illustrated in Fig. 1 . The computational grid, consisting of a $223 \times 46$ mesh of one-centimeter squares, is also shown in Fig. 1(c). The external guide field has a value of $500 \mathrm{G}$ and the poloidal $\mathrm{flux}$ in the annular gun barrel is $-1.94 \times 10^{6} \mathrm{G}-\mathrm{cm}^{2}$. 
(a)

Edge of computational grid

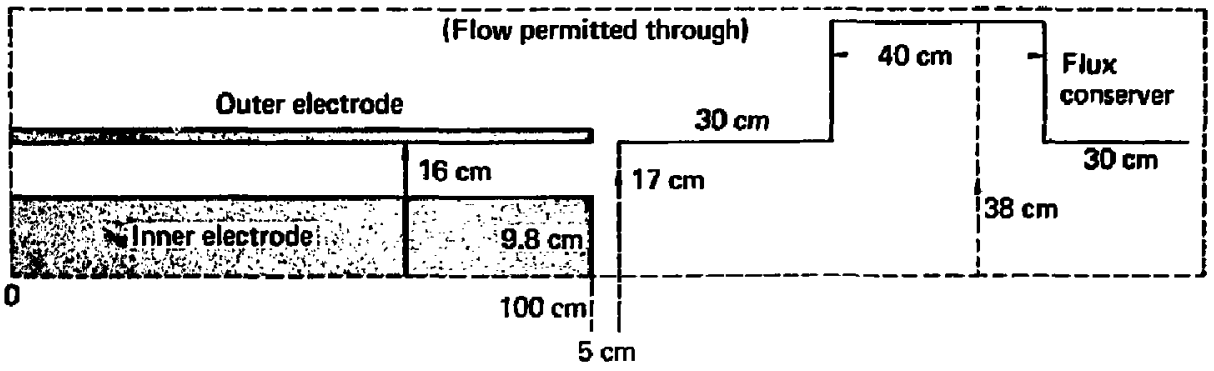

(b)

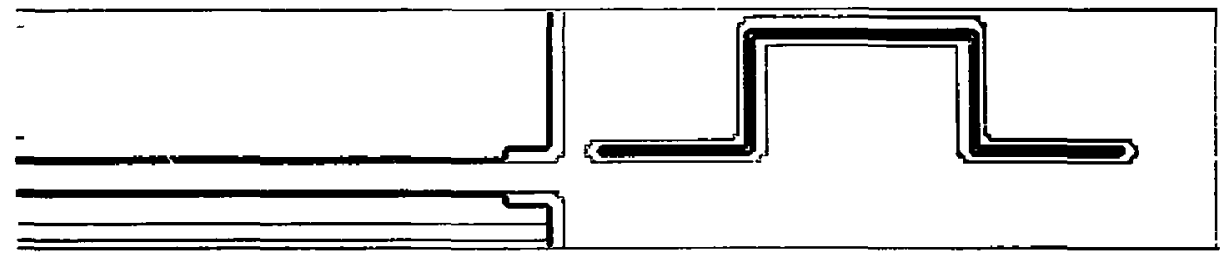

(c)

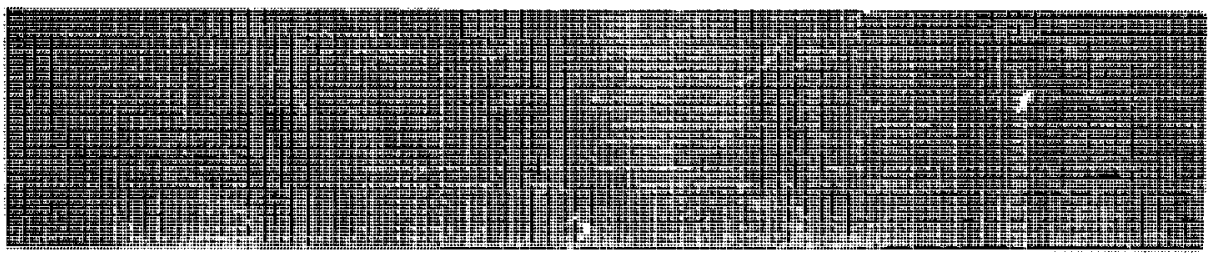

웄

FIG. 1. Geometry and computational grid. (a) Sizes of the exper:ment; (b) actual computer figure; and (c) computational grid. 
The gas fill was 3.125 atm cc. of equivalent deuterium (D), initially distributed according to a Gaussian profile centered about the mid-point of the gun

$$
p(z)=5.13 \times 10^{15}\left\{\exp -.0028(z-50)^{2}\right\}
$$

A uniform background density of $1.87 \times 10^{12} \mathrm{~cm}^{-3}$ was assumed in the guide space. The plasma temperature in the grid was initialized at $0.1 \mathrm{eV}$ for both the ions and the electrons, except in the region $22 \mathrm{~cm} \leq z \leq 28 \mathrm{~cm}$ where the temperature was increased to $5 \mathrm{eV}$ to initiate the discharge problem. A Saha iunization model was employed and the plasma resistivity is the sum of spitzer and electron-neutral resistivity and Sgro's anomolous resistivity. The geometry and external circuit parameters are given in Table I.

TABLE 1. Initial conditions of the experiment.

\begin{tabular}{|c|c|}
\hline capacitance, wfd & 0.058 \\
\hline inductance, nh & 50 \\
\hline resistance, $\Omega$ & 0 \\
\hline voltage, $k v$ & -35 \\
\hline External field guide & $0.5 \mathrm{kG}$ \\
\hline $\begin{array}{l}\text { Density profile in gun, } \\
\text { independent of radius }\end{array}$ & $\begin{array}{l}\rho(z)=1.7 \times 10^{-8} \\
\exp \left[-.0028(z-50)^{2}\right] 8 . \mathrm{cm}^{-3} \\
\equiv 5.210^{15} \exp \left[-(z-50)^{2} / 19^{2}\right] \mathrm{cm}^{-3}\end{array}$ \\
\hline Minimun plasma density in gun & $6.25 \times 10^{-12} \mathrm{~g} / \mathrm{cm}^{3}$ \\
\hline Plasma temperature in gun & $0.1 \mathrm{eV}$ (ions and electrons) \\
\hline $\begin{array}{l}\text { Initial value of } r A_{\text {f }}(=\text { poloidal } \\
\text { flux } / 2 \pi) \text { in inner gun electrode }\end{array}$ & $-0.309\left[16 \cdot \mathrm{cm}^{2}\right]$ \\
\hline
\end{tabular}


The initial density profile is illustrated in Fig. 2(a), and the initial isot sput of $\mathrm{r}_{e}=5 \mathrm{cv}$ is around $25 \mathrm{~cm}$. The code loes not carry the induction torm $(\partial E / \partial t)$ in Ampere's law, and so flux has to diffuse into the zun. However, the initial density and temperature allow the fielis to diftuse quit: rapidly up the gun barrel to ionize and accelerate the main mass t.f the bas i ill. The laboratory discharge displays eight iilaments at the gas valves at ju cm, and rutıre simmlations will try to force breakdown nearer this region.

in intarmediate view of the rundown is shown in Fig. 2(b), and the separation of fast and slow plasmas is already apparent. The electron temperature is bighest at $45 \mathrm{~cm}$, behind the density peak at $60 \mathrm{~cm}$. Th: current patin runs down the outer electrode (anode) and through the plasma in the region of the density peak to drive the magnetic piston, which pushes and heats the plasma. Tive $1 / r$ fall-off of this $b$ field accounts for the radial variation of the plasma velocity. Momentum llow and electrun temperature are show in Figs. 2(d) and (e).

the state of the plasma as it emerges irom the gun is shown in Fig. 3.

\section{TOROID FORNATION}

Tire density, Llux, and momentum llow as the plasma runs into the tlux conserver, where the field lines reconnect, and how a compart toroid is Lormej, dre shown in Figs. 4-9. The Eirst visible reconnection (Eig. o) takes place around 0.8 usecs as plasma flows out of the gap between the gun and the ilux conserver. The thonentum tlow just inside the tlux conserver nas just Jevelopud a stagnation point (Fig. 8) and some plasma is beginning to flow back iaco tae gun. At this time, the forward momentum has slowed ousicurably, to be followed, at $t=10.1$ Hsecs, by expansion into the main shamber. The coroid forwation takes place between 11.9 and 15.6 usecs in a uanner similat to that fir:i discussed by Fetschek (see Ref. 6) for coroid recunticetion. The toroid bounces gently in the main chamber as the bulk of the plasma accelerates back into the gun. 
(a)

(b)

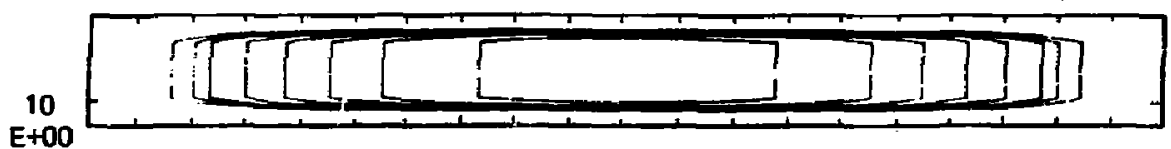

(c)

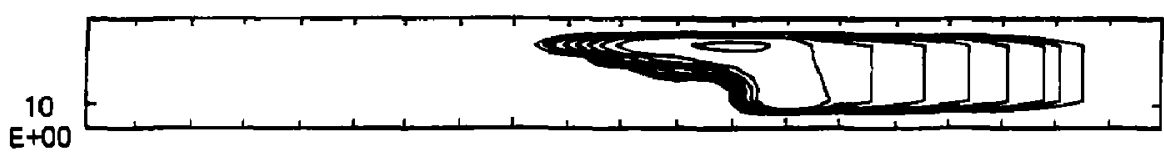

(d)

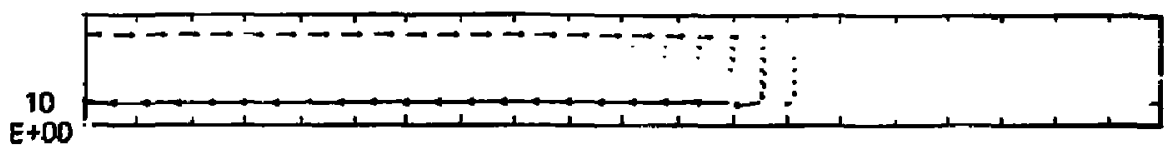

(e)
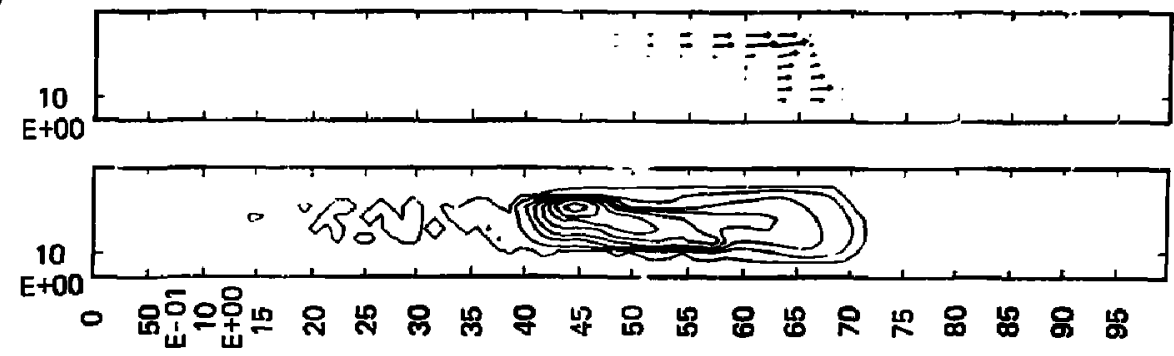

FIG. 2. Plasma density simulation (a) initial gas density contours in the gun; (b) density at $2.9 \mathrm{secs;}$ (c) poloidal current-flows through anode, across the plasma, and back to the cathode at $2.9 \mathrm{\mu secs} ;$ (d) monentum flow at 2.9 usecs; ( $(\epsilon)$ electron temperature at 2.9 usecs. Peak is still back in Loss density region. Density and temperature contours vary by factors of 10.0 . Peak density is $10^{15} \mathrm{~cm}^{-3}$. 
(a)

(b)

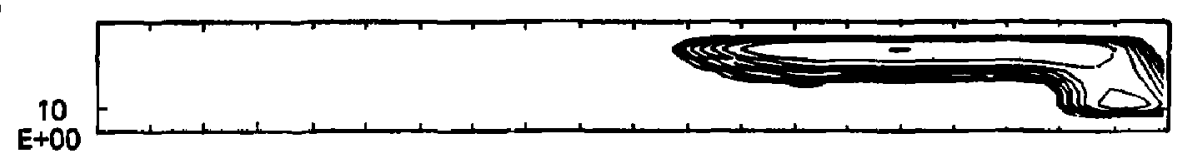

(c)
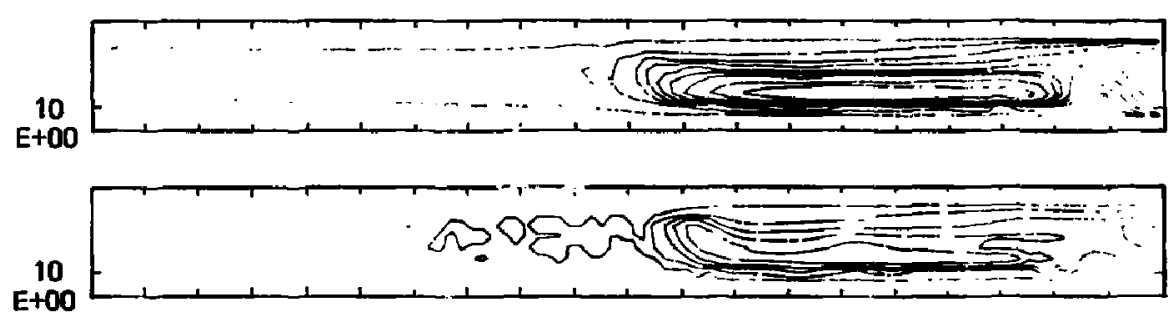

(d)

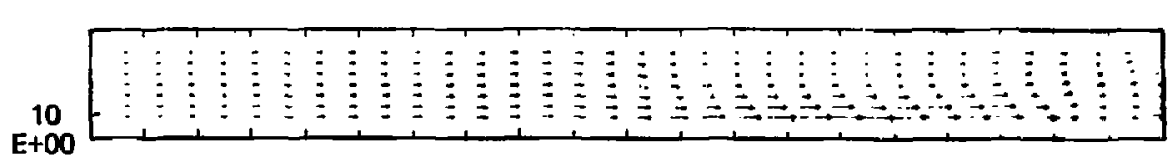

(e)

(f)
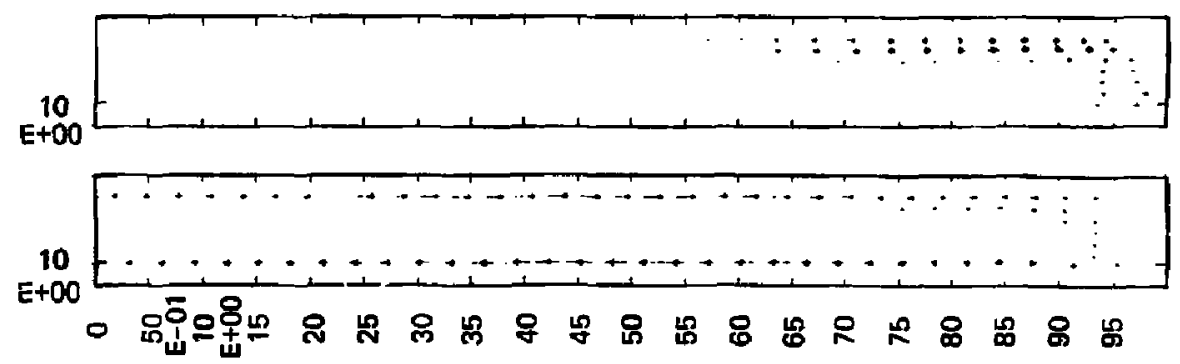

FIG. 3. Final conditions at $t=3.8 \mu$ secs of gun rundown. Figures are (a) density, (b) ion temperature, (c) electron temperature, (d) flows velocity, (e) plaswe monentum, and (f) current flow. Contour levels differ by factor of 10.0. 

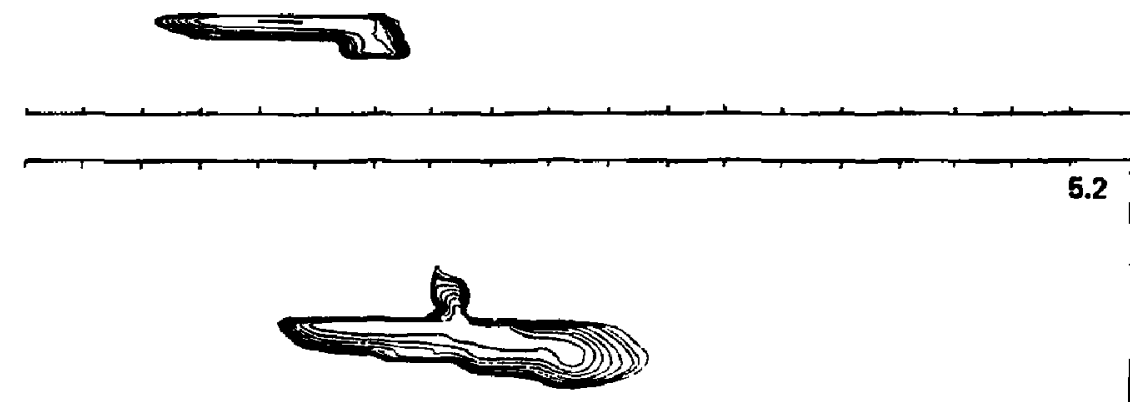

6.6
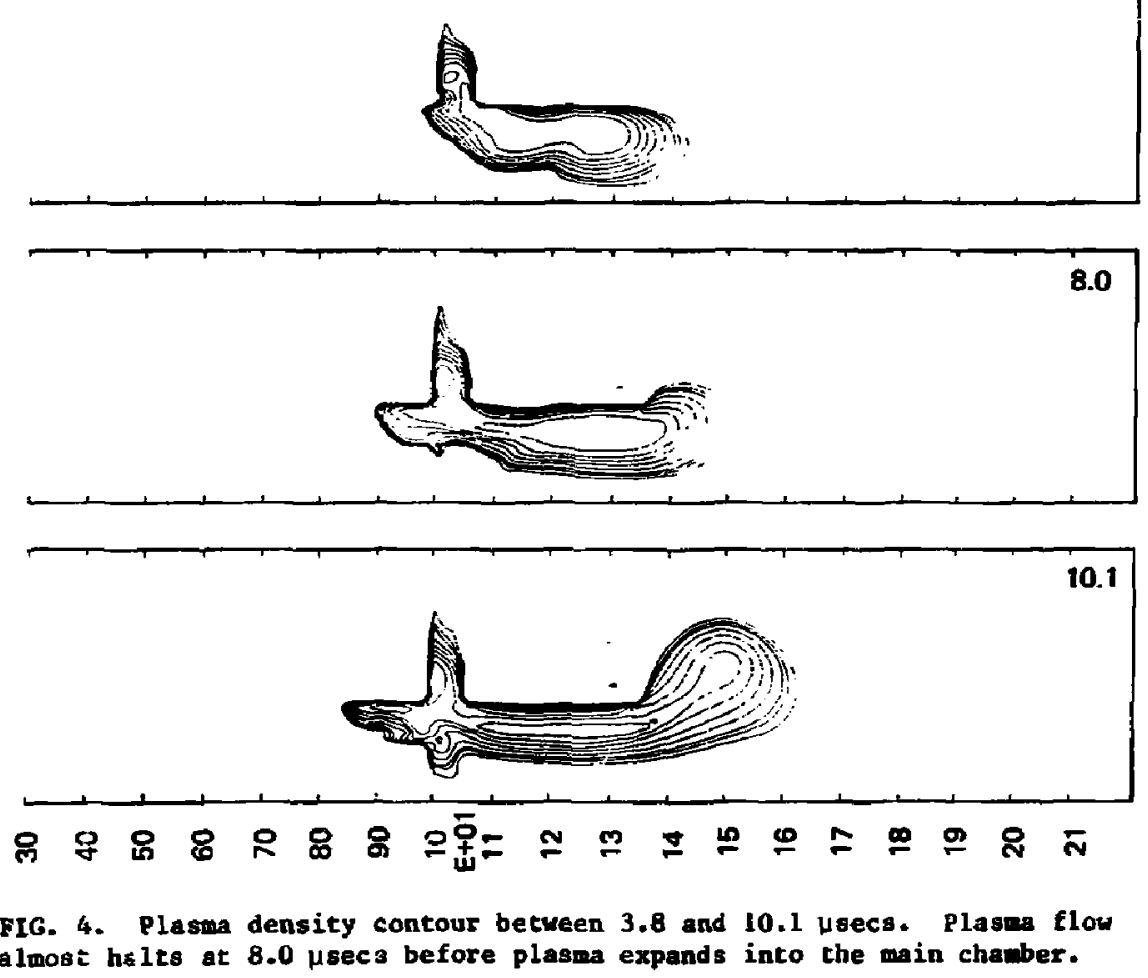

$-8-$ 

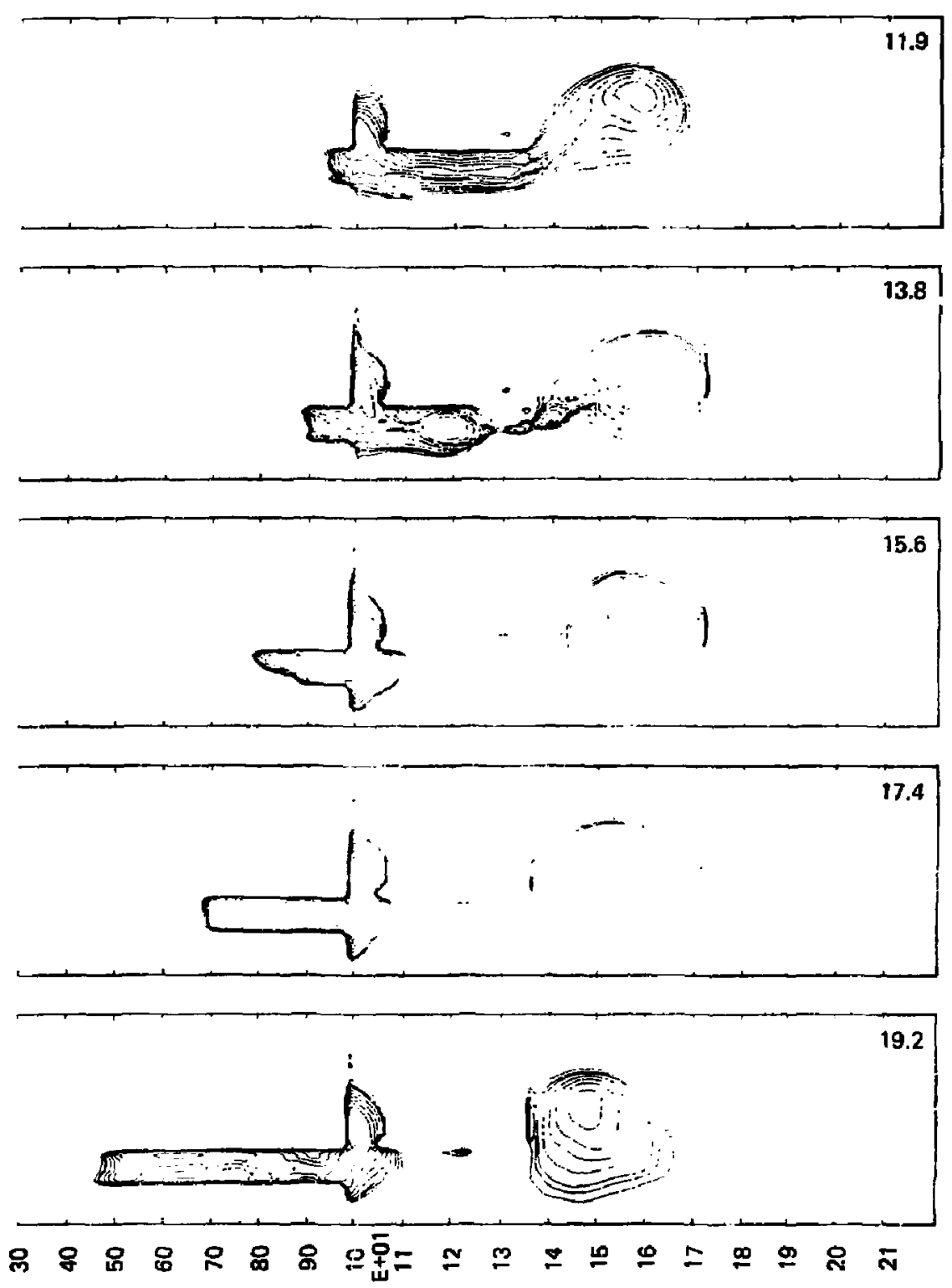

FIG. 5. Plasma density centours between 11.9 and 19.2 usecs show complete toroid formation an's plasma retreating into the gun. 
Flux
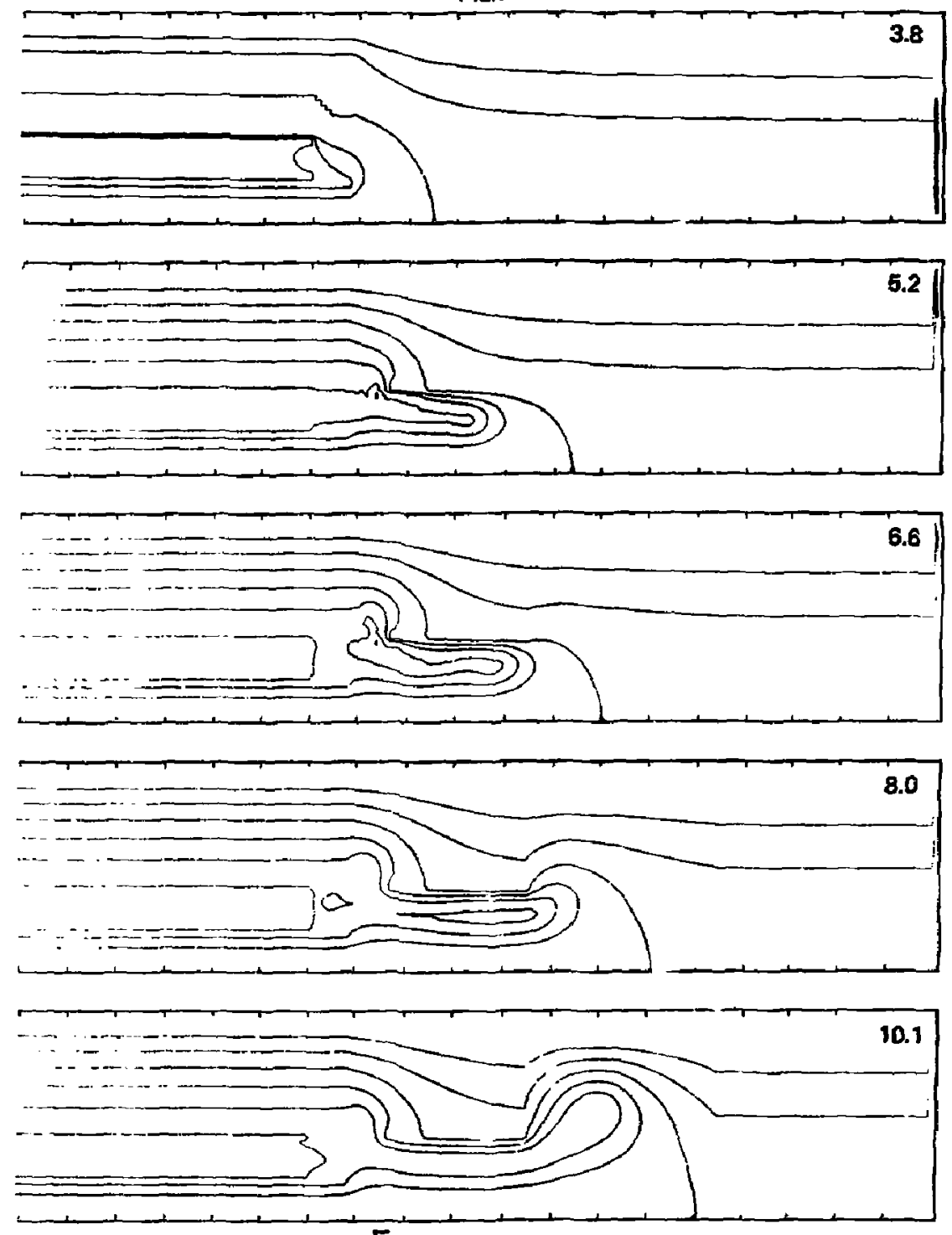

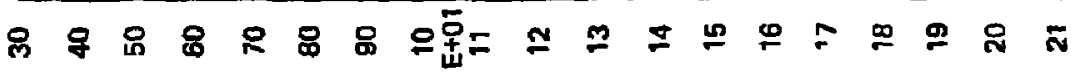

EIG. 6. Flux contours between 3.8 and 10.1 Hsecs. A tiny anount of flux reconnects at 8.0 usecs around the gun-concerver gap. 

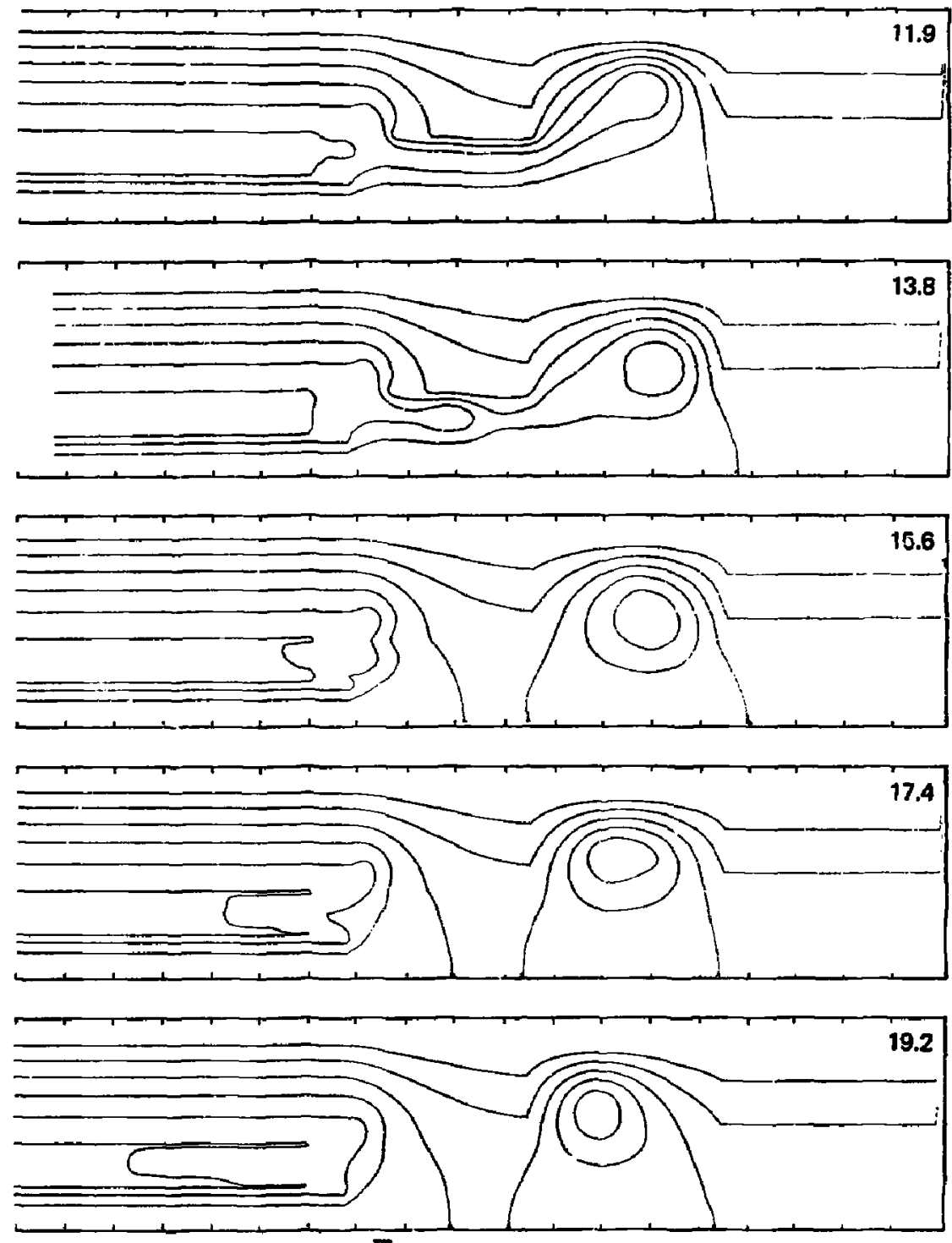

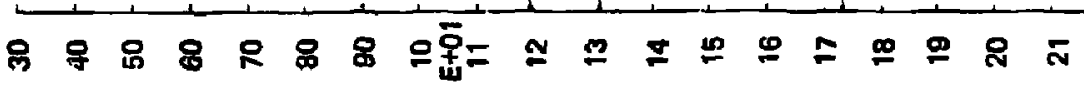

FIG. 7. Flux contours between 11.9 and 19.2 hoecs shows completion of the reconnection process. 

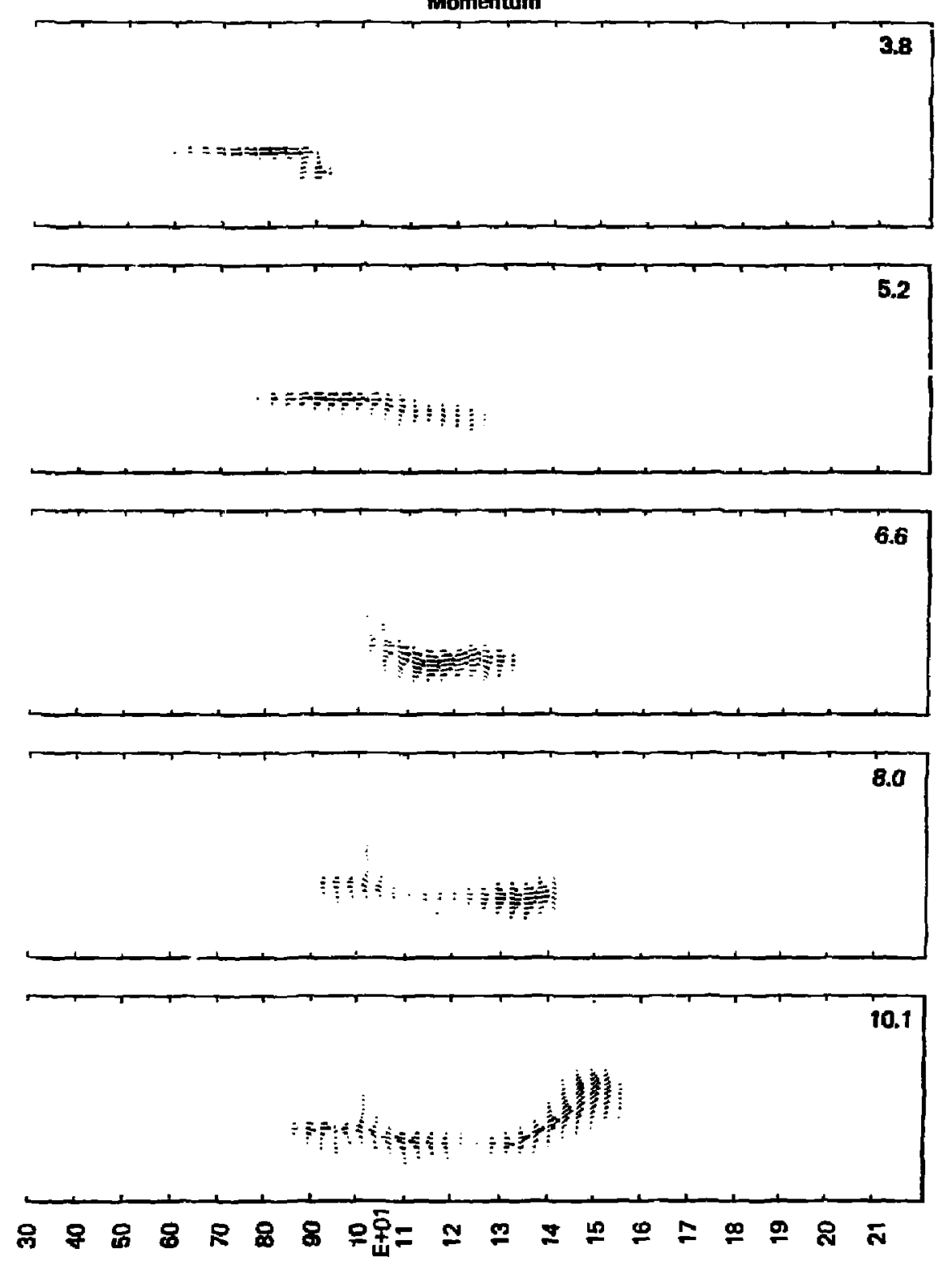

FIG. 8. Plecan monentw vectors between 3.8 and 10.1 paecs. Observe stagnation of the flow at 8.0 usecs. This atagnation point at 10.1 Hsecs is in the reconnection tone. 

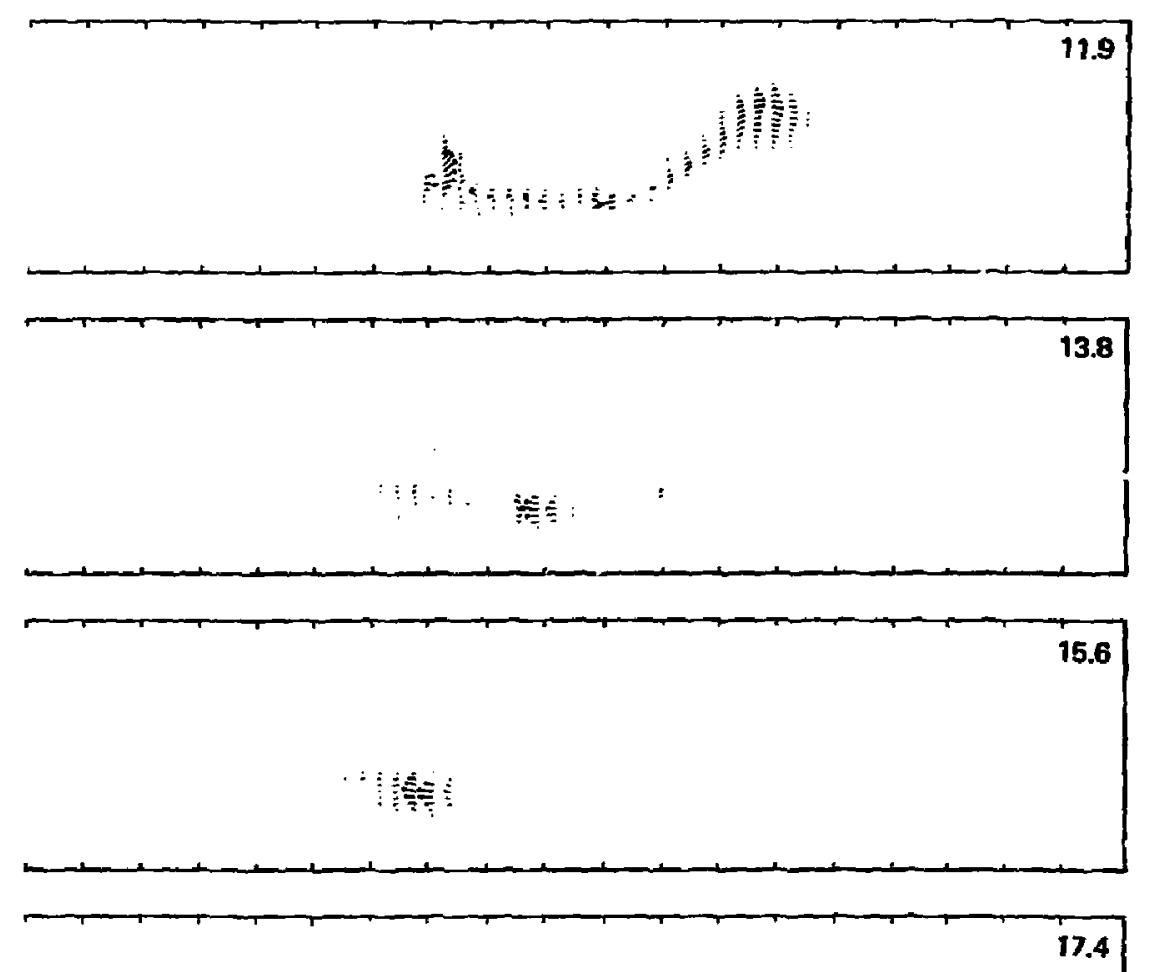

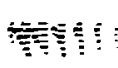
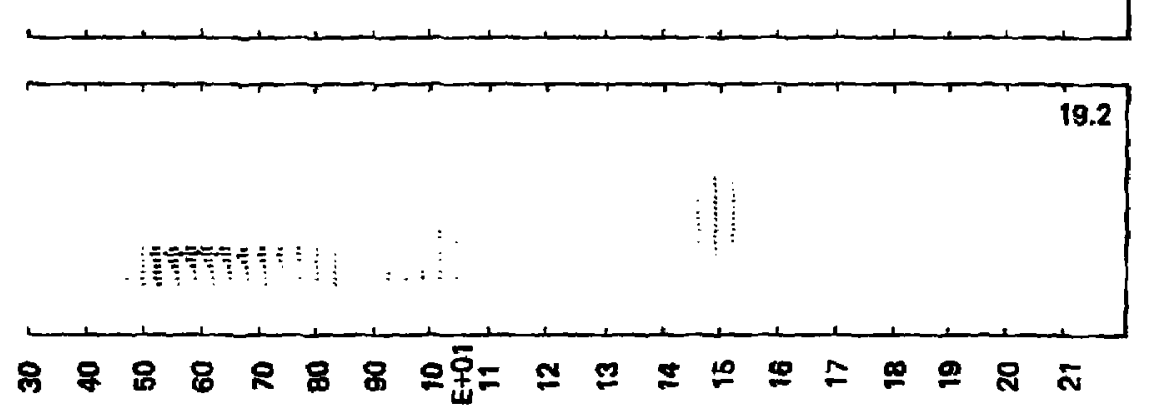

FIG 9. Plasme monentul between 11.9 and 19.2 psecs. Observe that the compact toroid it almost atetionary. 
There are several characteristics of the plasma gun discharge voltage and current which coincide with stages of the plasma evolution described above. At point $A$ ( $t=3.8$ usecs), in Fig. 10, the gun current is at its maximum negative value of $-600 \mathrm{kA}$ as the plasma emerges from the gun. The first reconnection is taking place as the current swings through zero and the plasma flow reverses in the region of the gun-conserver gap (Fig. 8 ).

At point $C(t=10 \mu \operatorname{secs})$, the current is at its maximum positive value of $240 \mathrm{kA}$ and the plasma has just started to expand into the main chamber of the flux conserver (Fig. II). Formation of the compact toroid takes place between $D$ and $E$ when the voltage has dropped close to zero (Eig. 12). The reconnection processes evidenily clamps the voltage around -1 keV. The effects of the positive current flow are barely seen in the flux conserver until this point in time. In the laboratory experiment, the gun short-circuits near the insulator and no positive current flows in the gun at all. Future simulations will invoke this crowbarring effect.

\section{DETAILS OF RECONNECTION}

One-dimensional cross-sections of the experiment at $r=13 \mathrm{~cm}$ are shown in Figs. 13-17. The main chamber is between 135 and $175 \mathrm{~cm}$. The first density plot shor's the differer se between the expanding plasma and the denser column destined to retreat inte the gun. The reconnection point is arour:s 130 $\mathrm{cm}$, where the density is lowest and the resistivity (Fig. 14) is anomalously high. Fig. 15 displays separately the classical part of the resistivity on the same scale as Fig. 14. The very high resisciyity back in the gun bore arises from the minimum plasma density and temperatures allowed in the simulation, $p_{\min }=5.10^{12} \mathrm{~cm}^{-3} \tau_{\min }=0.1 \mathrm{eV}$, and is irrelevant to the reconnection processes in the flux conserver. Reconnection is dominated, evident $1 y$, by anomalous resistivity. The magnetic field in fig. 16 reflects the flux contours of Fig. 7 at this time. The negative $B_{z}(-1.5 \mathrm{kG})$ in the expander is part of the reversed flux which is reconnecting. The field ( $4 \mathrm{kG})$ in the conserver between 110 and $140 \mathrm{~cm}$, and the negative $B_{z}$ at the gun muzzle, is part of the guns' initi.l poloidal field. This section through the field profile varies because of the inward radial flow of plasma in the reconnection zone around $140 \mathrm{~cm}$. 

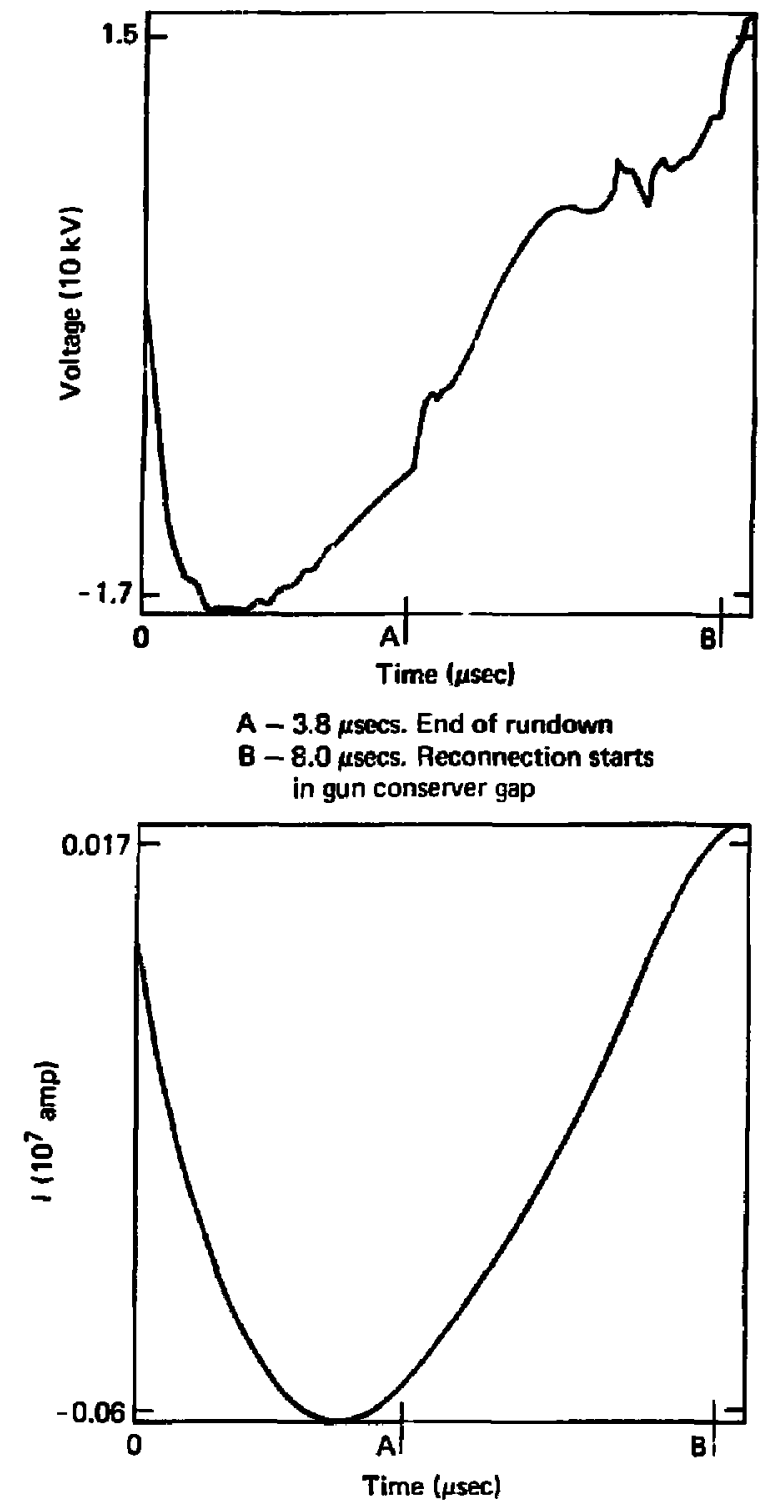

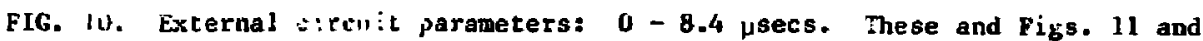
12 stluw vultage anu current variations during the discharge. The code dumps and restarts many times in a run, so time histories are collected from many files. 


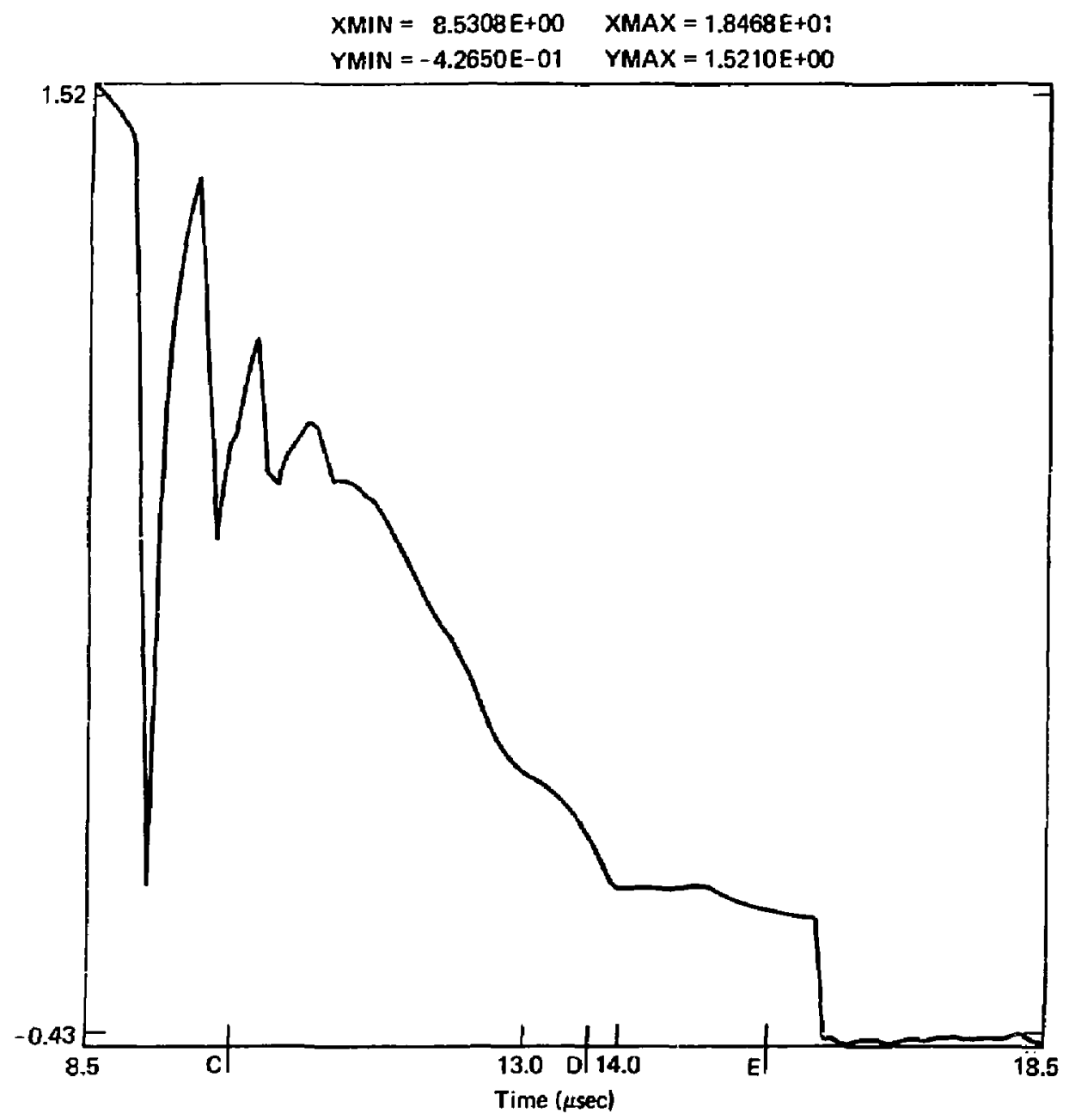

FIG. 11. External circuit parameters: $t=8.5-18 \mu \mathrm{sec}$. 


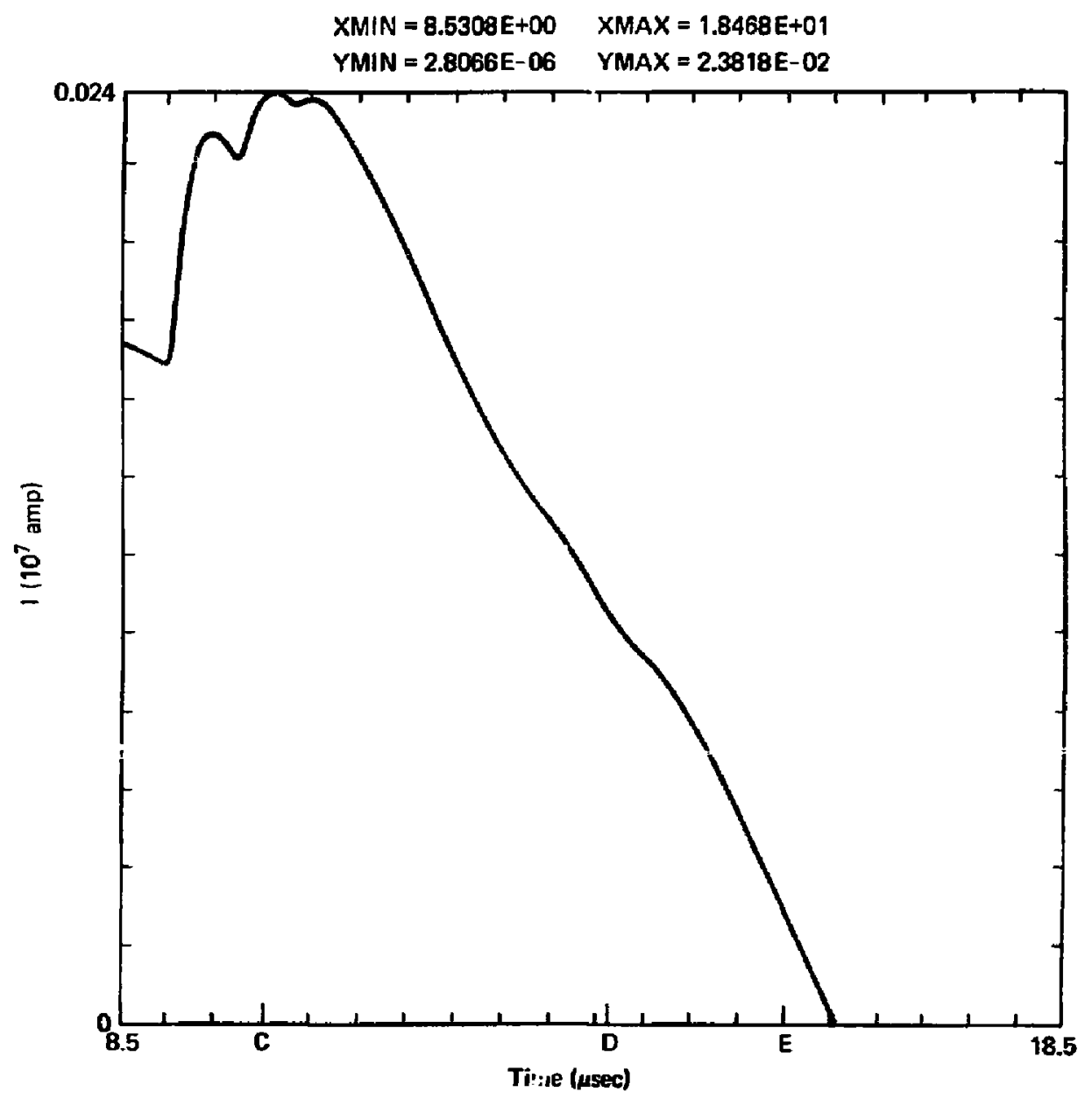

FIG. 12. Total gun current falls steadily to zero. 


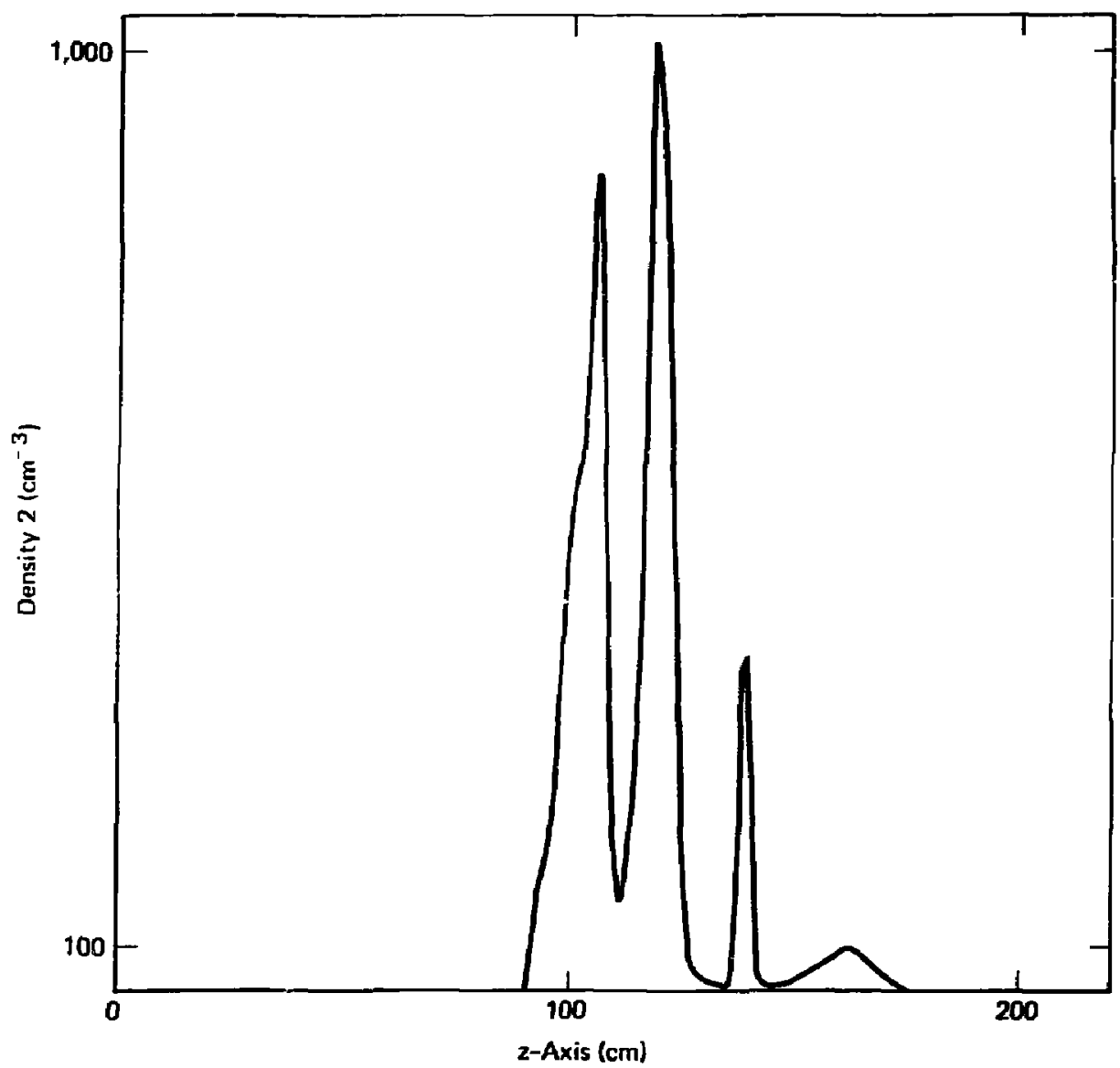

FIG. 13. Plasma density at $r=13 \mathrm{~cm}, t=13.6 \mu \mathrm{sec}$ shows compact toroid at $2.10^{14}$ and the bulk of the plasma peaking at 4.1015 . 


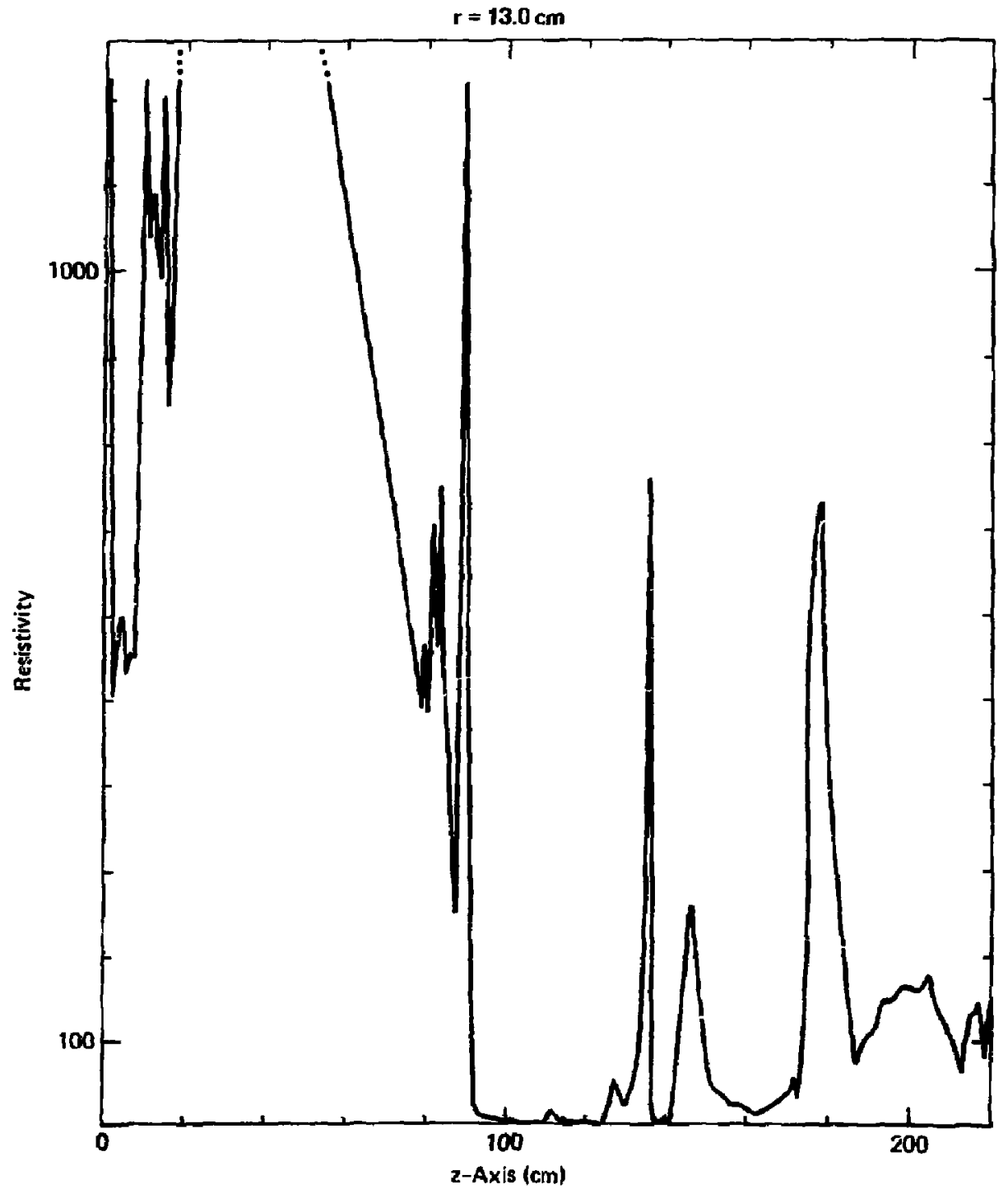

Fiv. 14. Total resistivity at $r=13 \mathrm{~cm}, t=13.6 \mu \mathrm{sec}$, is largely anomolous. $-19-$ 


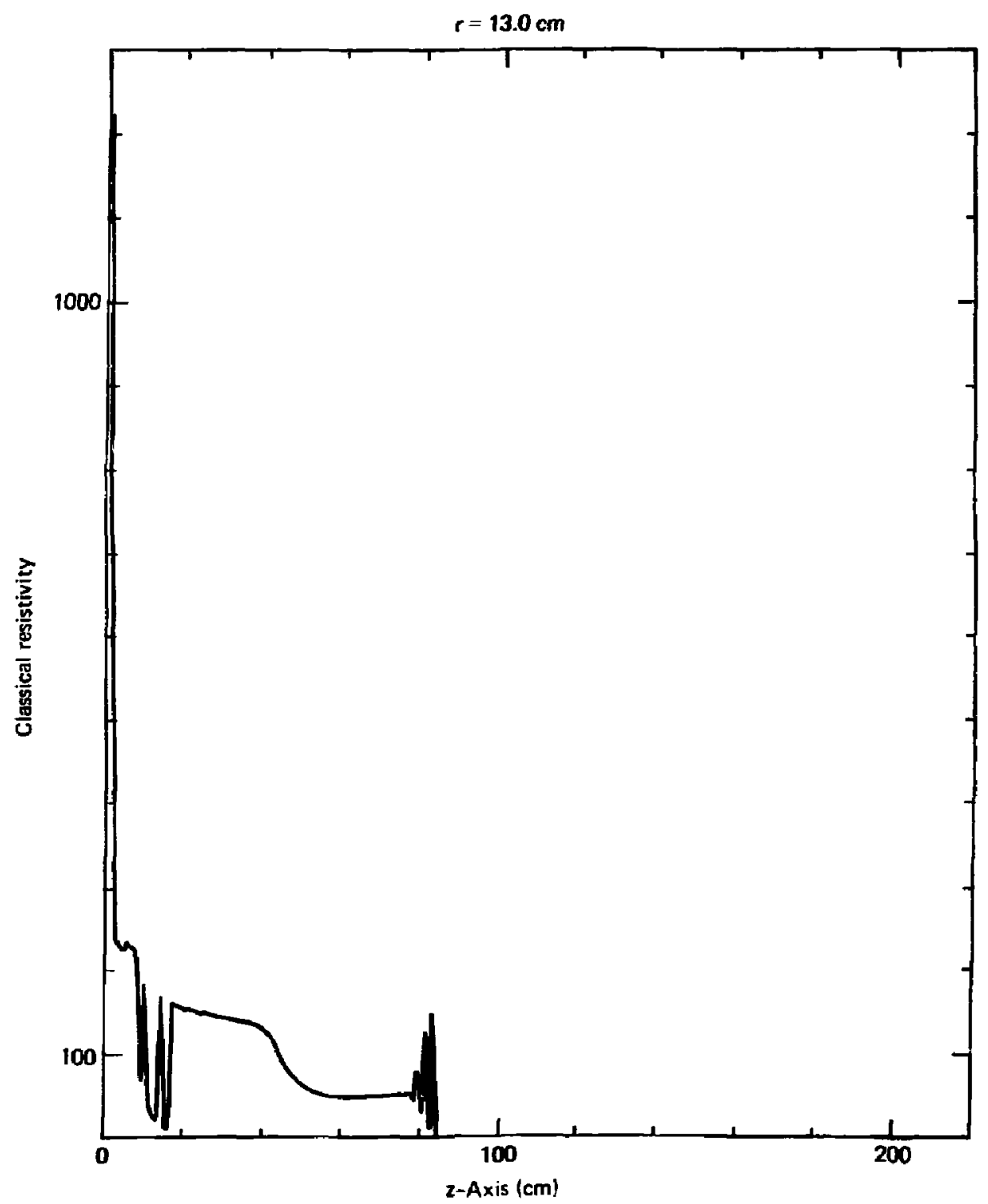

EIG. 1). The classical resistivity at $r=13.0 \mathrm{~cm}, t=13.6 \mu \mathrm{sec}$, is very low in the hot plasma in the flux conserver. 


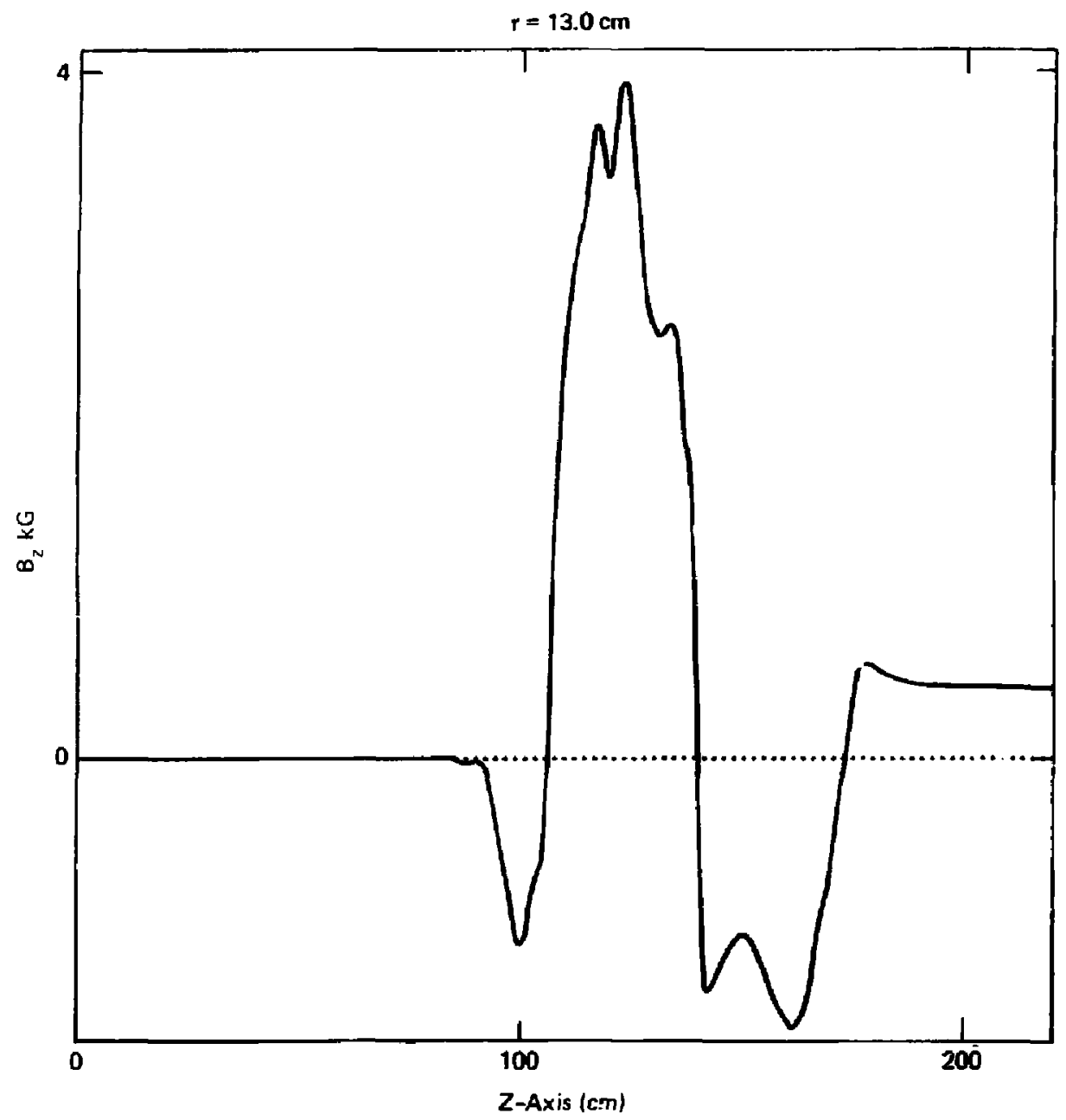

Fli. 16. $B_{z}(c)$ at $r=13.0 \mathrm{~cm}, t=13.6 \mu \mathrm{sec}$ shows reversed field as the turus forms.

$$
-21-
$$




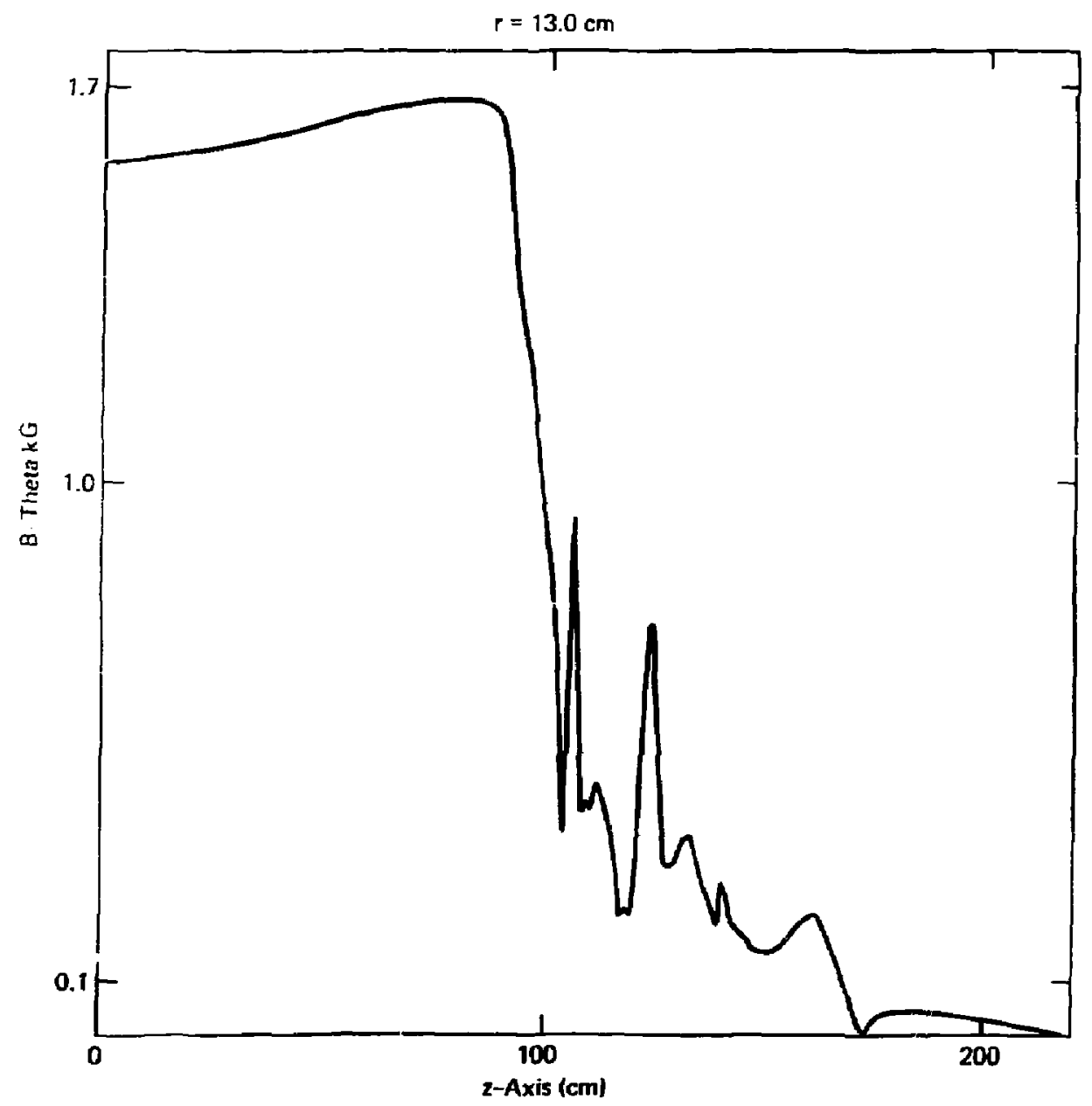

FIL. 17. Toroidal magnatic field at $r=13.0 \mathrm{~cm}, t=13.6 \mu \mathrm{sec}$. 
jit rxaminution al Figs. -7 snows that $B_{z}$ traces along the axis ot the duveritury axporiment aro much less informacive of the details of the

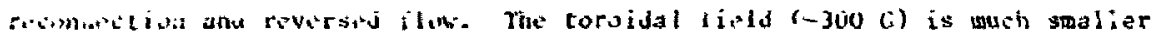
tian :ine poloidal tiali througtout the flux conserver (Fig. It).

diadial plots it line entrance co the expander, shere $z=114.5 \mathrm{~cm}$, sluh that tue plaina risides in a hollow cylinder of radius close to that of

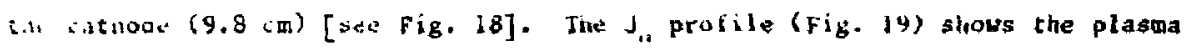
curreit and the large reverse current induced in the cupper walls of the conserver. Charactristically, the current paked at che untside of the ilasmi culumn. Ta: rosistivity (fig. 20) shows laräe il in the low-densily

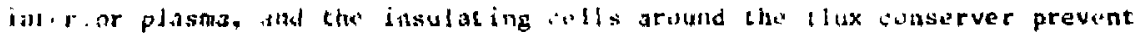

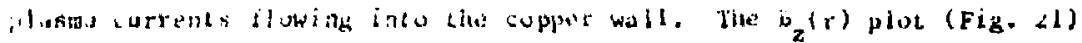

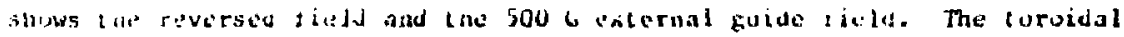

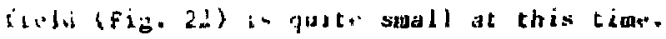

THE CUNPACT TOROIL

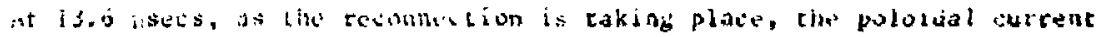

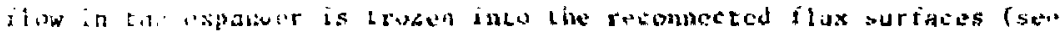

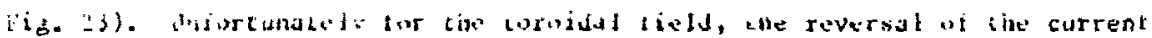

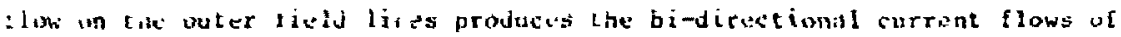

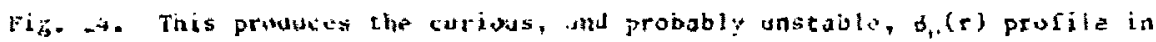

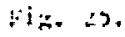

like remaining sequence (fís. 2u-2S) shows density, b and J..(r) Jlong

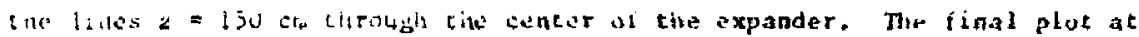

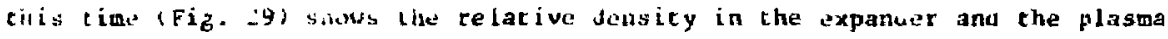
Lowing torough the gun conserver gap at $r=2+\mathrm{cm}$.

laumetric plots ul Jansity and 1 Iux at 15.9 Hsecs are diven in Figs. gu and 11 , and they illustrate the ralutiva ambuncs at ach extracted from the

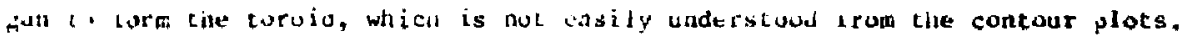
characterist les of toe famal coroiu dre sumarized in iable 11 . equidjlent laboratory data are not yet avallable. Ine current densify is sfill high enough to caus: the resistivicy ro oe quite anomalous. 


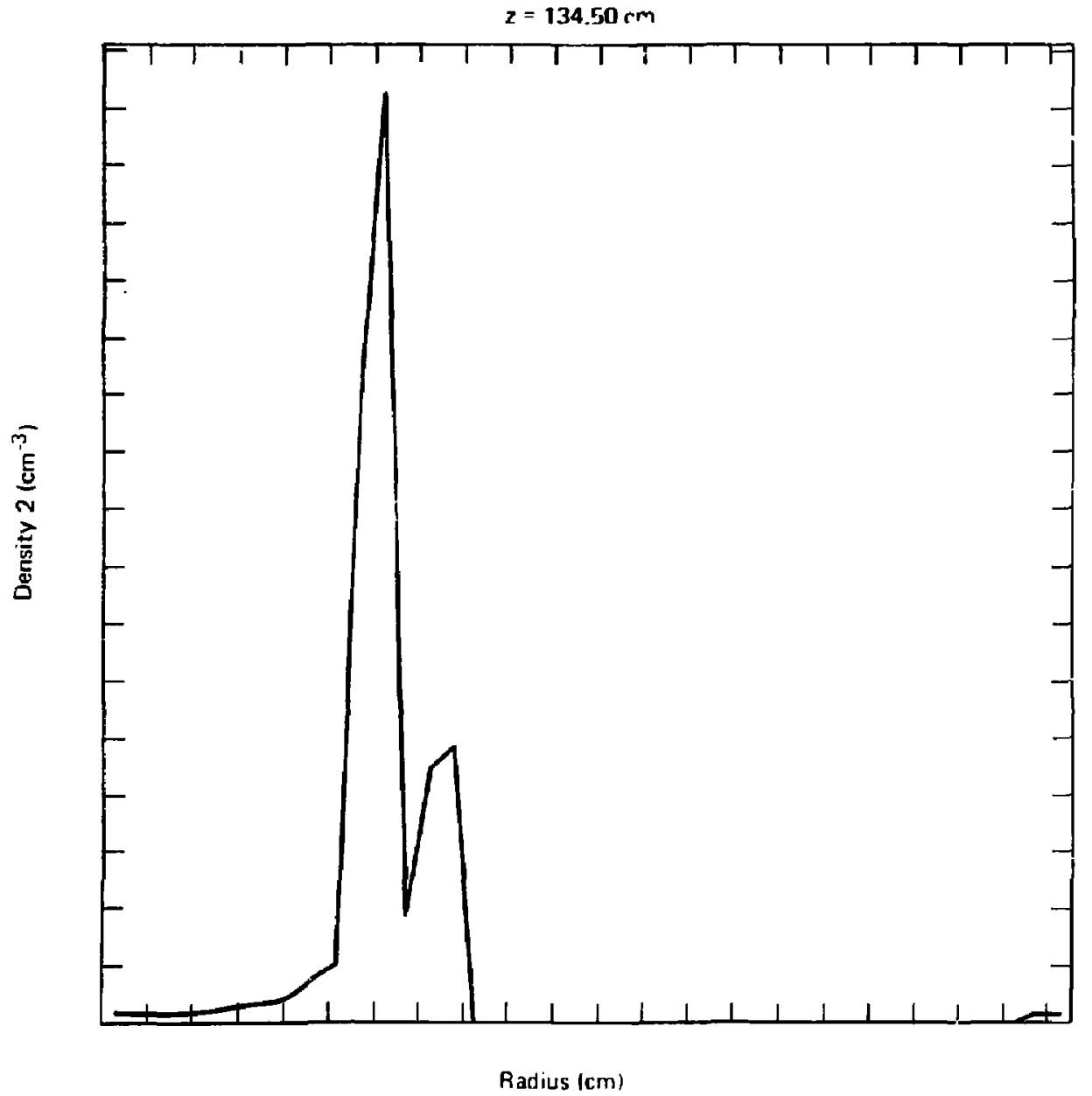

Fı. 1d. Density or entrance to Elux expander at $z=194 \mathrm{~cm}, t=13.6 \mathrm{Hsec}$. Plasma lies in a hollow cylinder. 


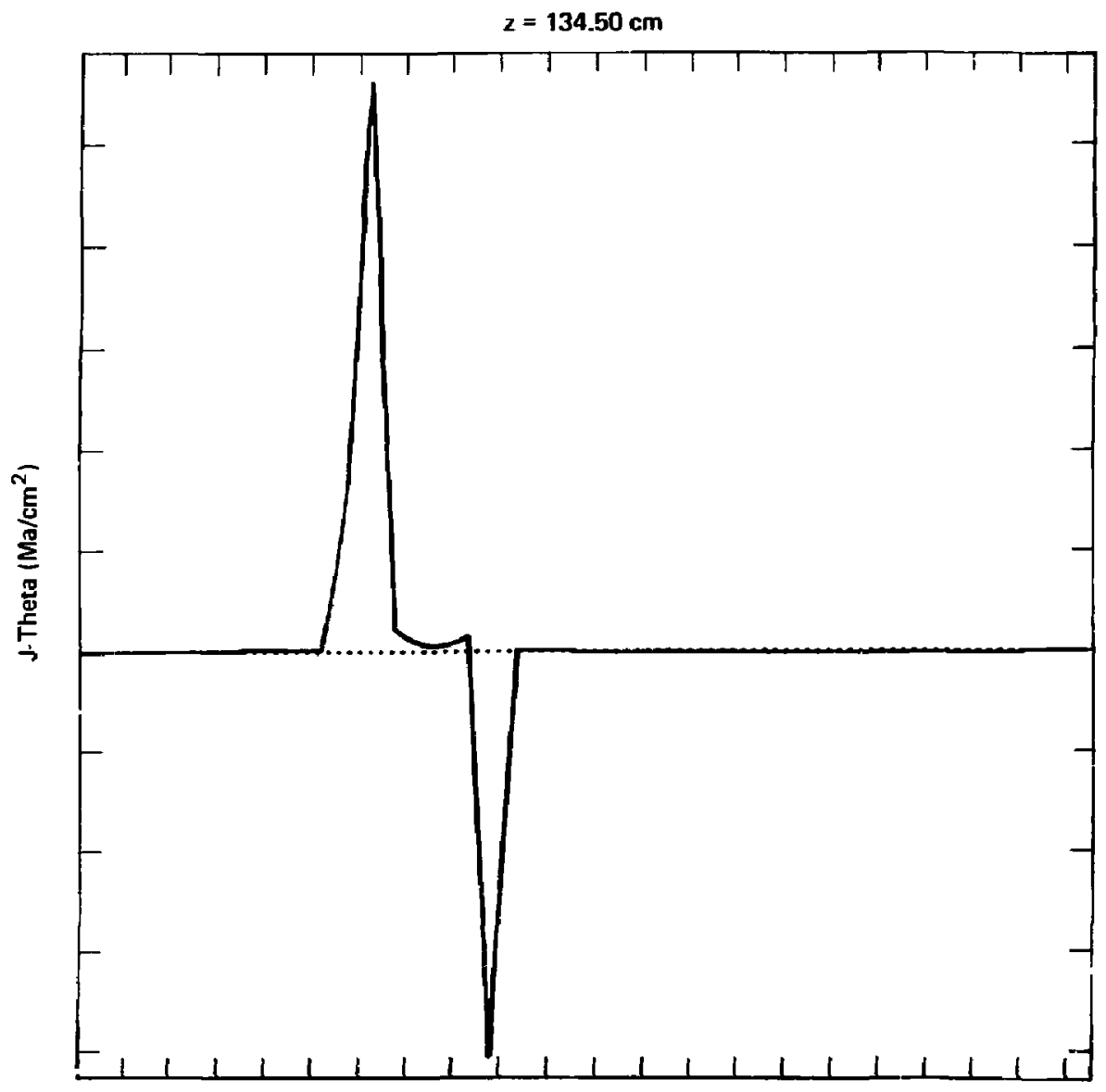

Radius $(\mathrm{cm})$

FIC. 19. Toroidal current at $z=134 \mathrm{~cm}, t=13.6 \mu \mathrm{sec}$ shows image current in I lux cunserver well at $17.0 \mathrm{~cm}$. 


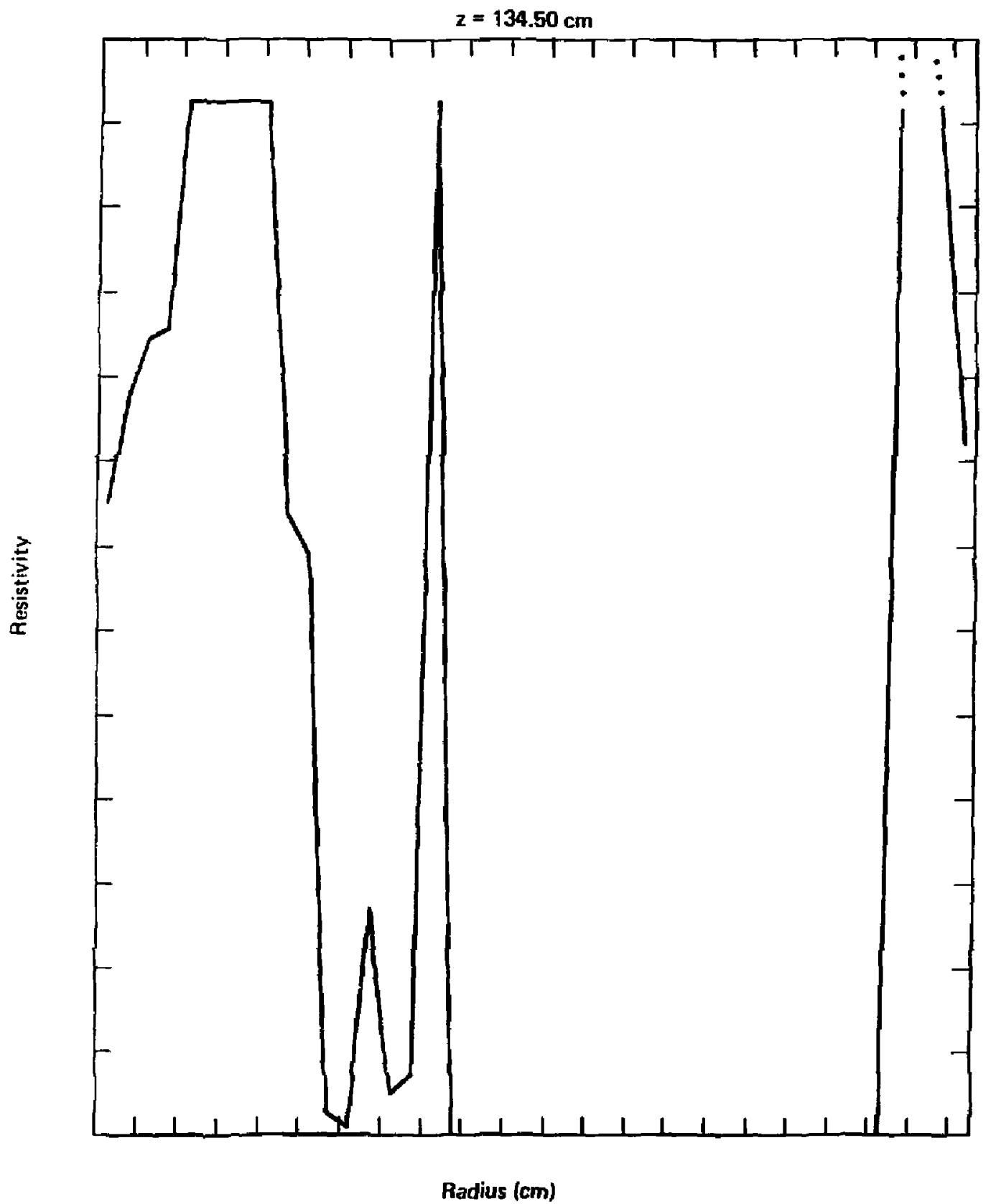

FiG. 20. Resistivity at $z=134 \mathrm{~cm}, t=13.6 \mathrm{psec}$ shows plasma and insulating zunes. 


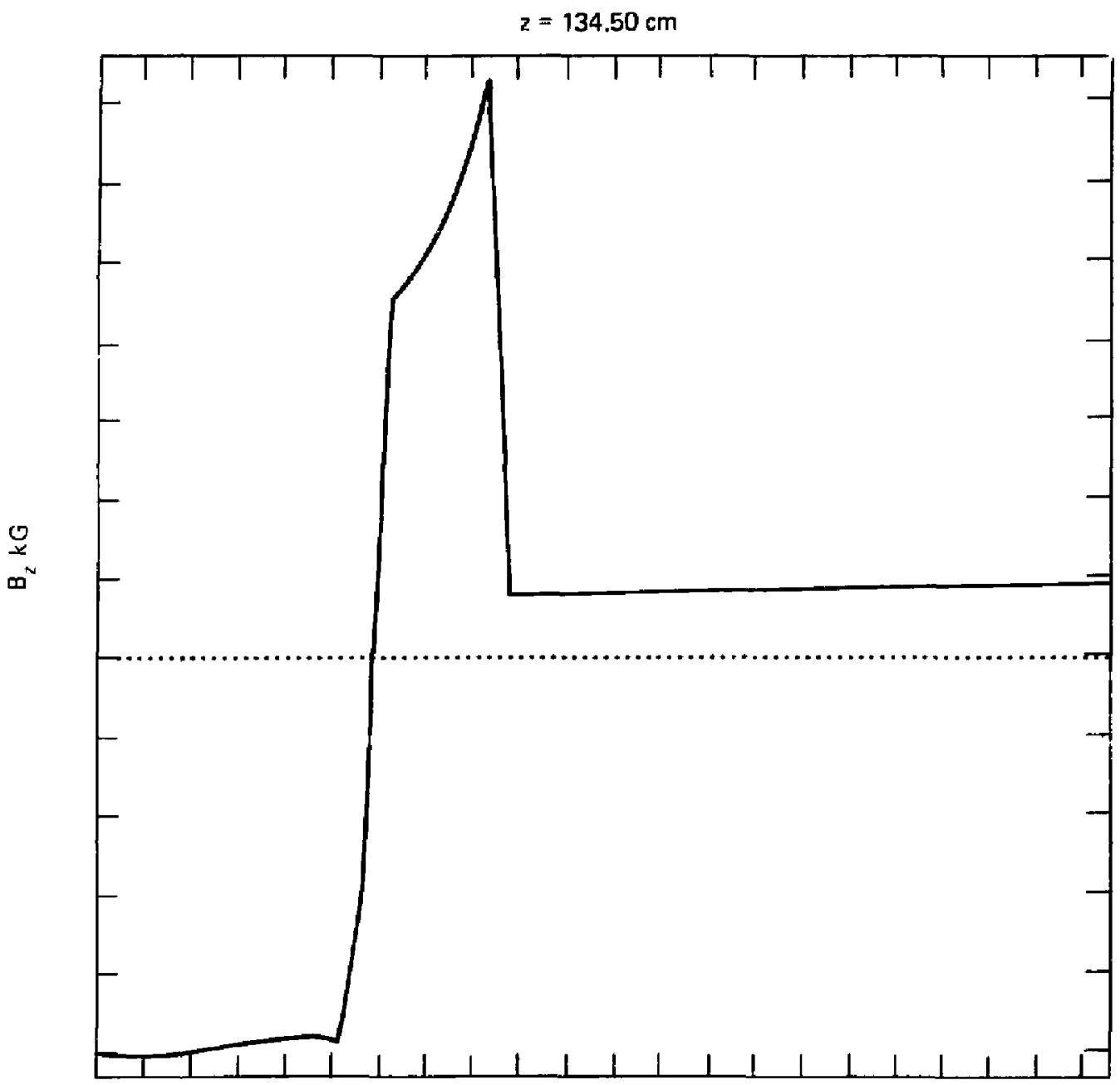

Radius (cm)

FIG. 21. $B_{2}(r)$ at $z=134 \mathrm{~cm}, t=13.6 \mu \mathrm{sec}$ shows reversed field contiguration with $2.5 \mathrm{kG}$ on axis. 


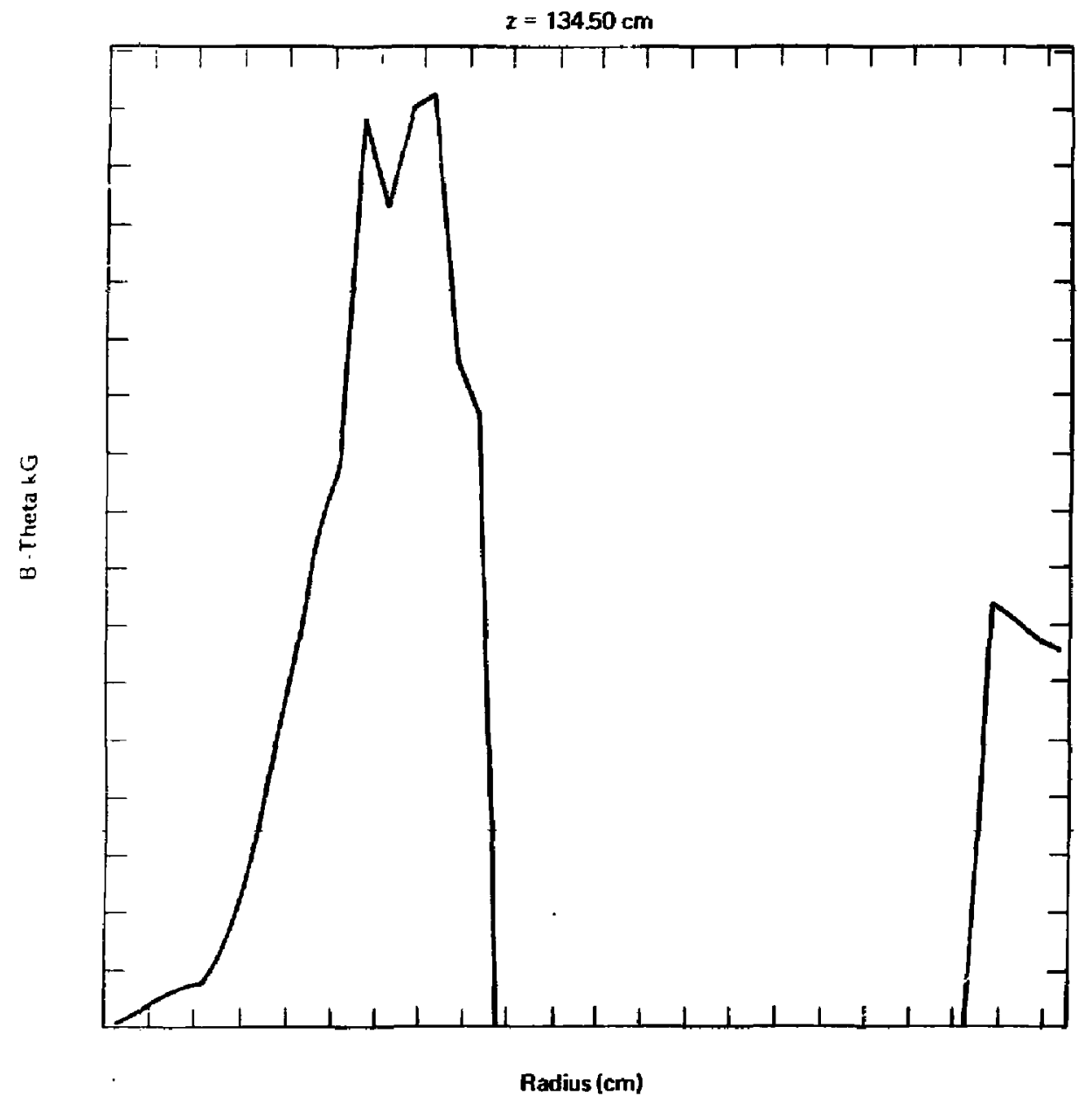

FIG. 42. Toroidal magnetic field at $z=134 \mathrm{~cm}, t=13.6 \mu \mathrm{sec}$ is only $0.3 \mathrm{kG}$ compared with poloial ifields of 2-3 kG. 


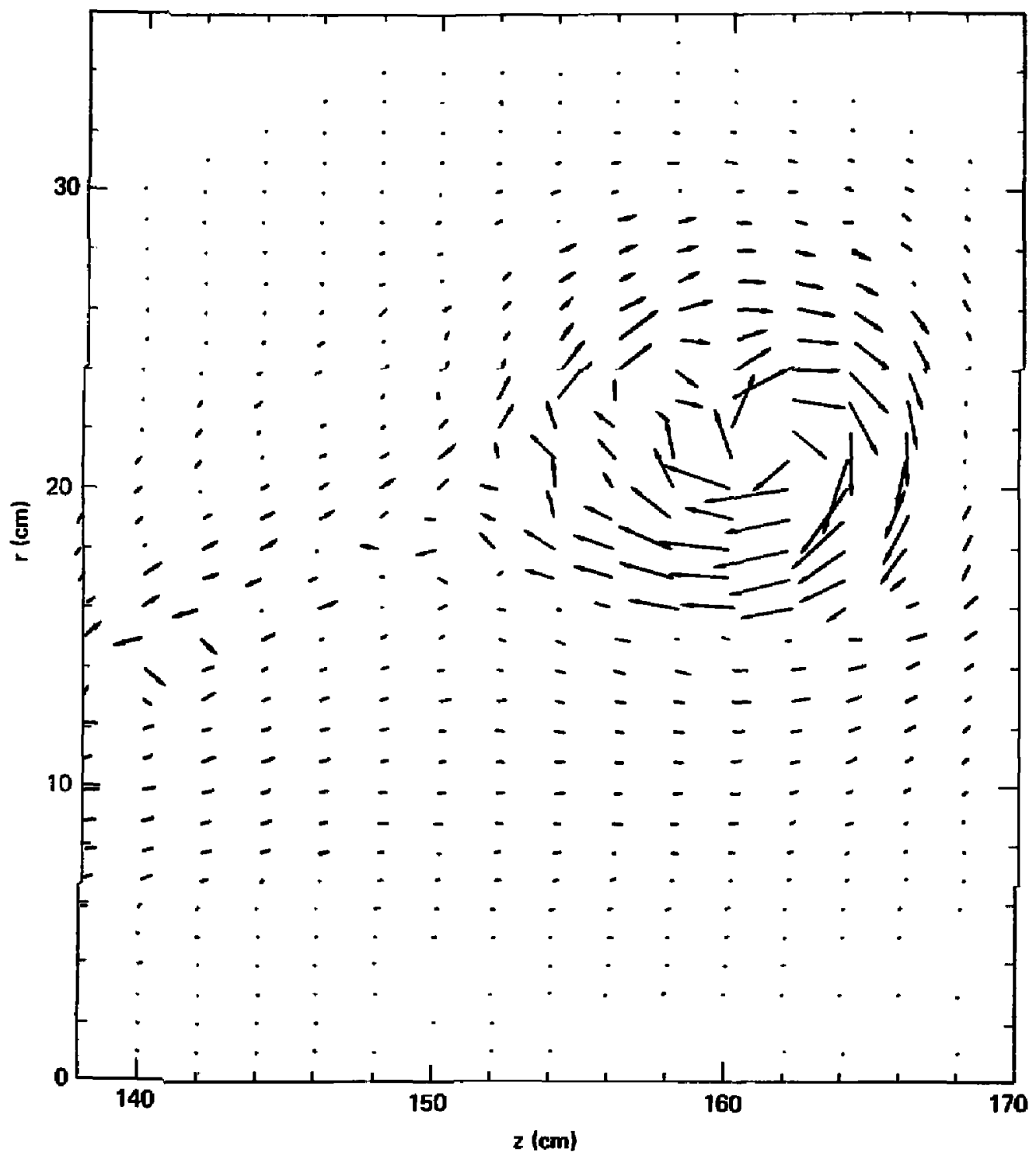

FIG, 23. Poloidal current flow at $13.6 \mu \mathrm{sec}$ in compact torus shows positive and negative flow which uiminish the total toroidal magnetic field. 


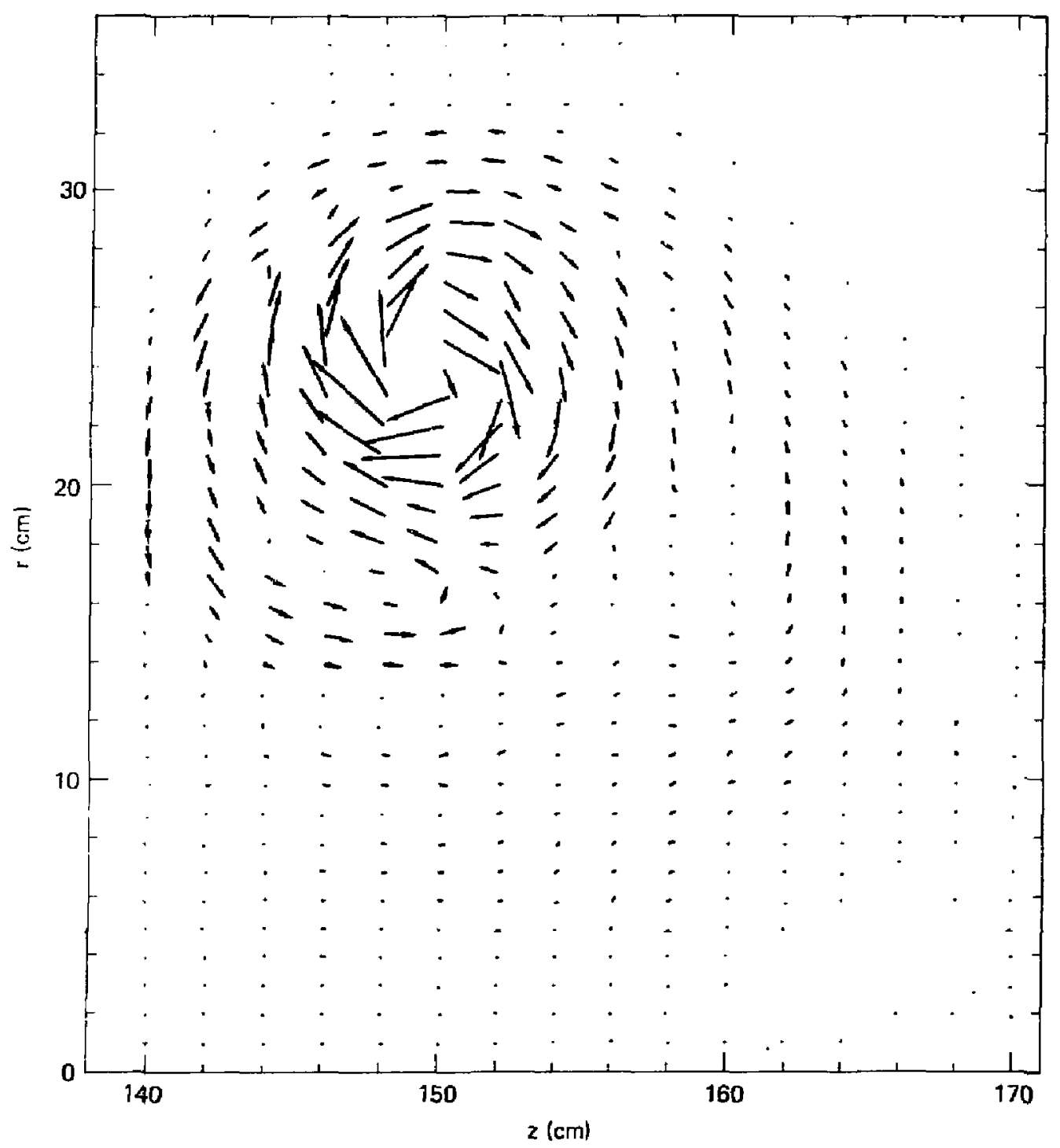

FIG. 24. Final current pattern in compact torus at $19 \mu$ sec. Laboratory gun shoots out the positive current flow. 


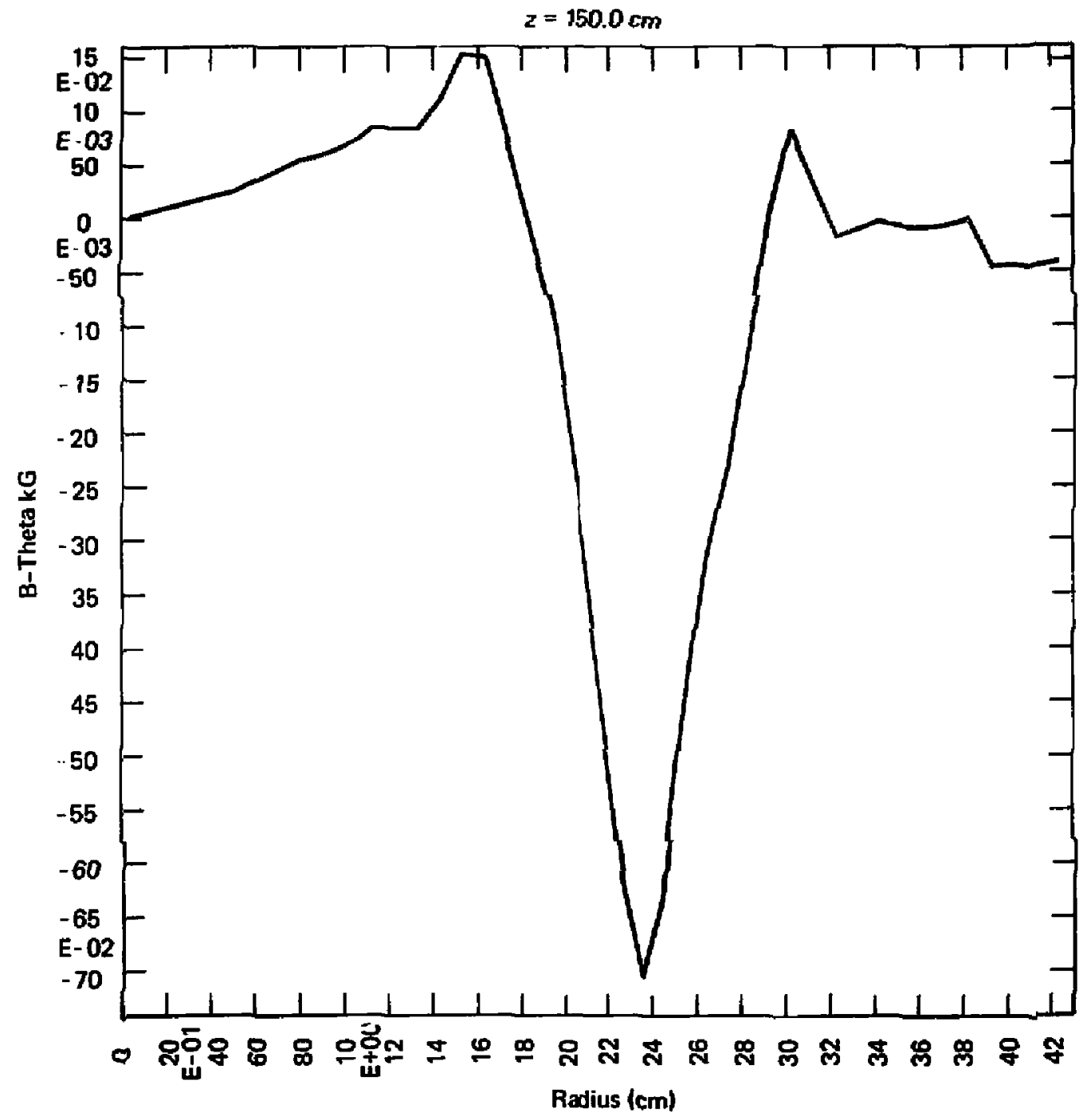

FLl. 25. Toroidal magnetic field profile through the center of the toroid shows positive and negative $B$. 


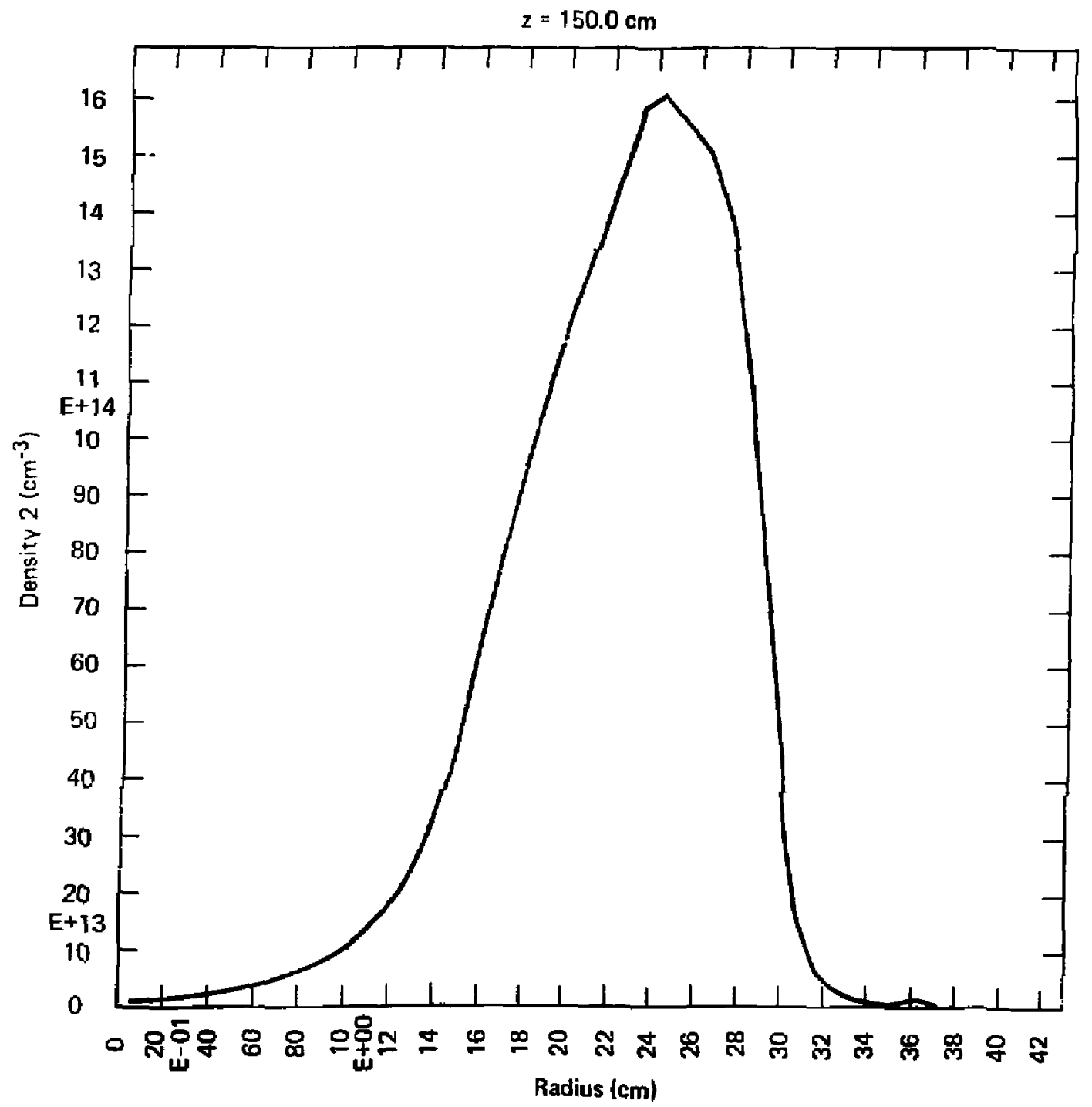

FIG. 26. Final density profile in toroid shows ring-like plasma. 


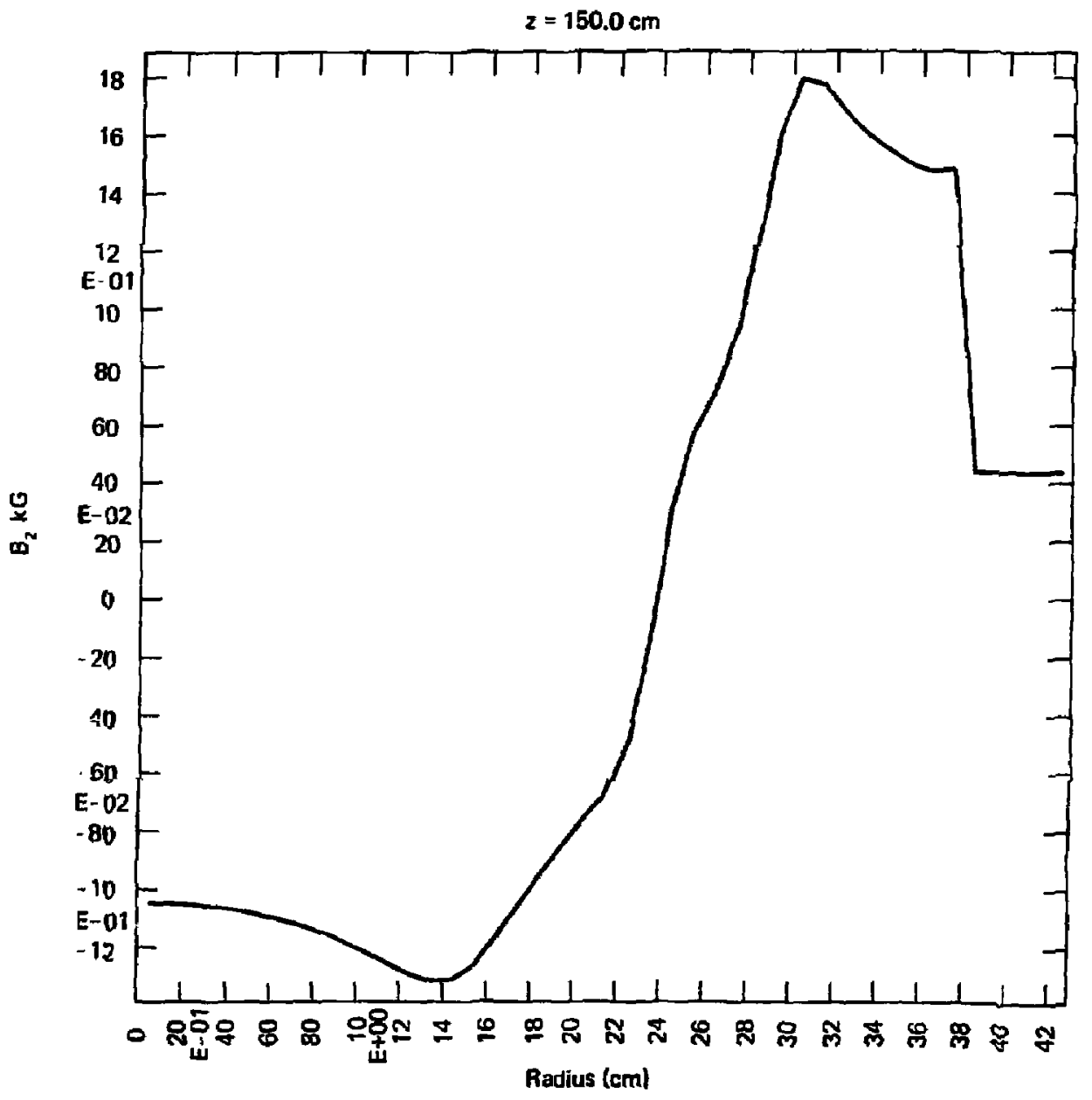

FIG. 27. The $B_{z}$ profile in toroid. 


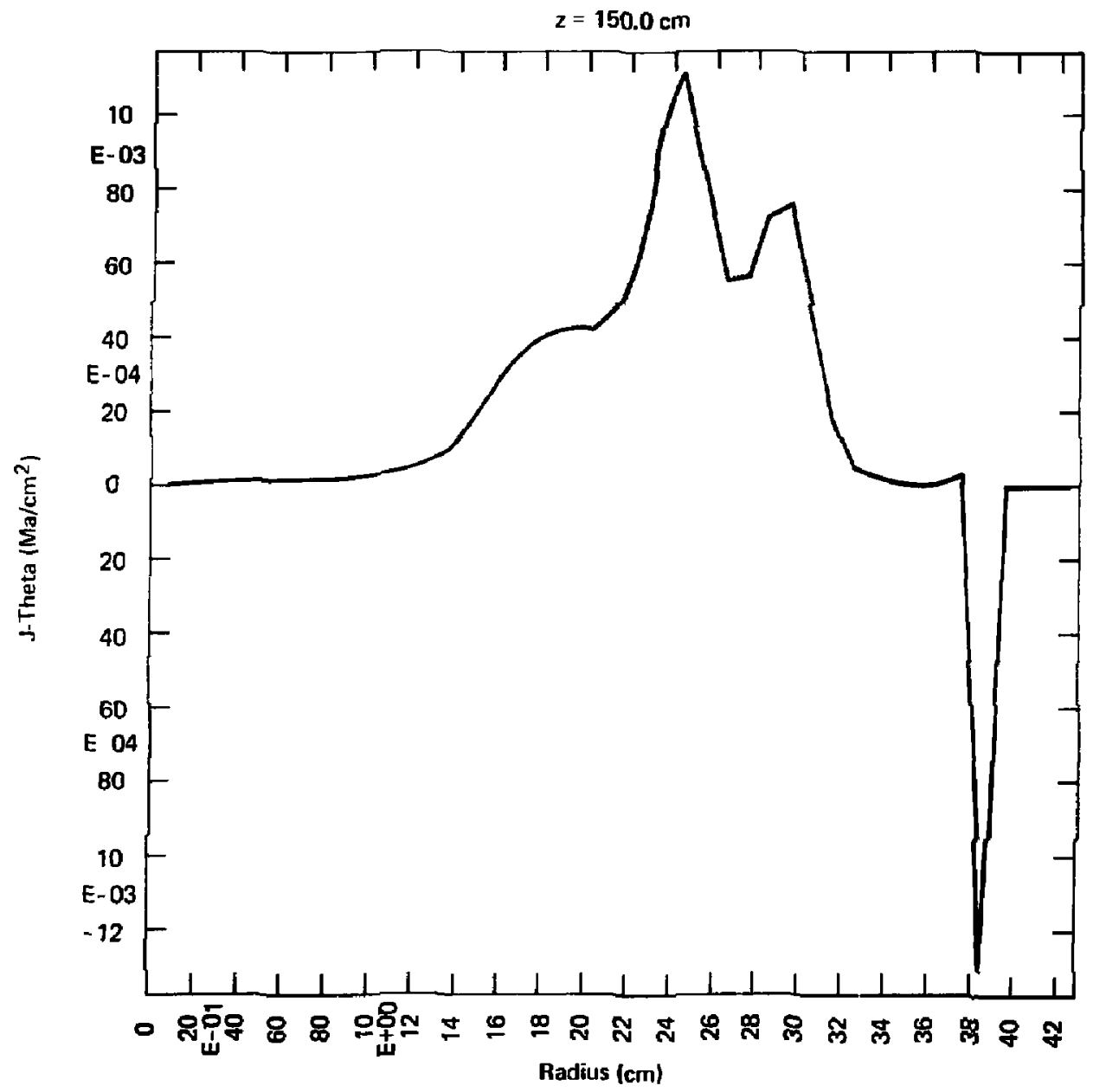

FIG. 28. Toroidal current profile in toroid and image current in congerver wall. The peak is close to the density peak. 


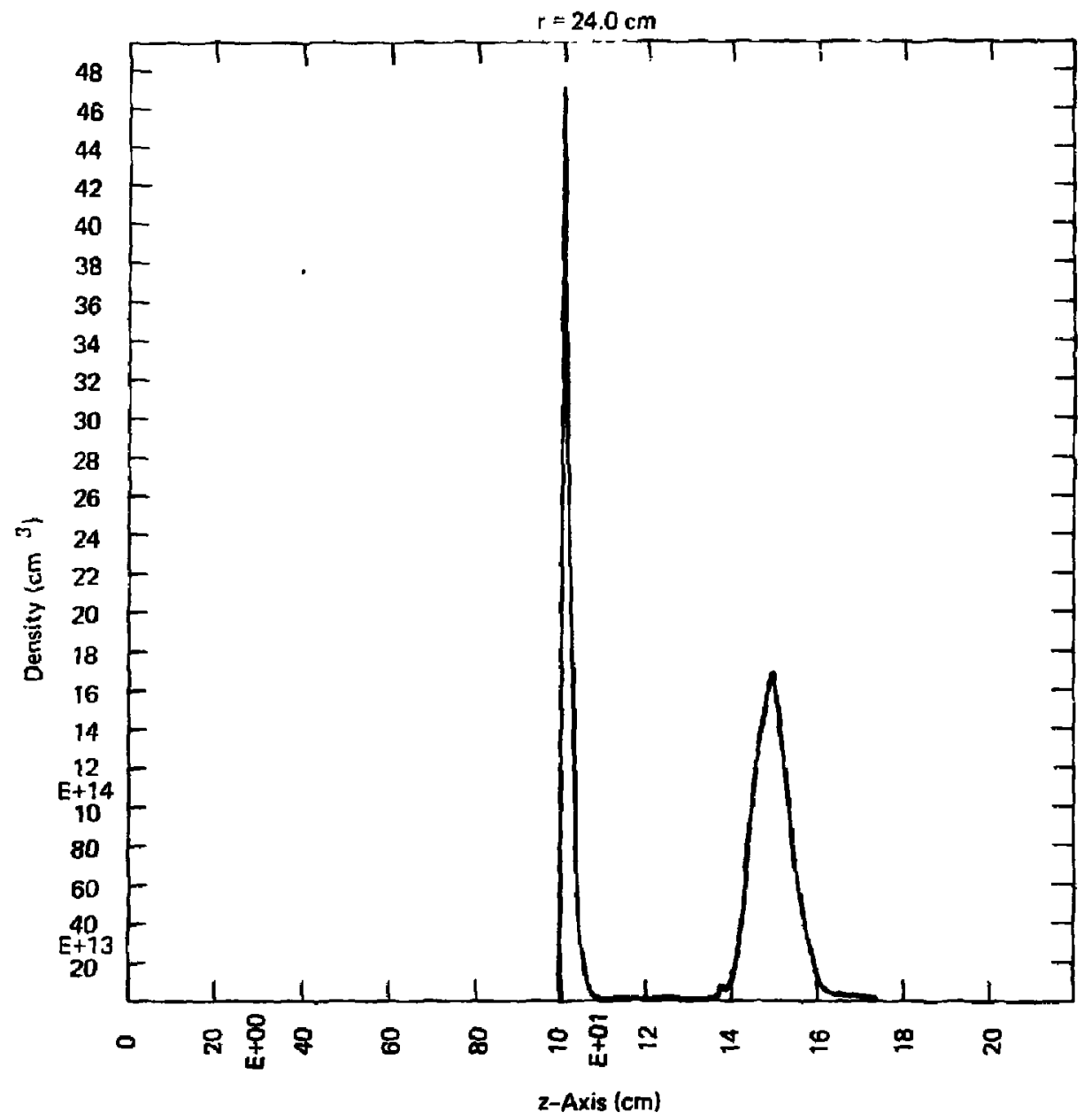

HIG, 29. Density at $I=24 \mathrm{~cm}, t=19 \mu$ sec shows compact toroid and plasua llowing througl gun-conserver gap. 


\section{Densitv 2}

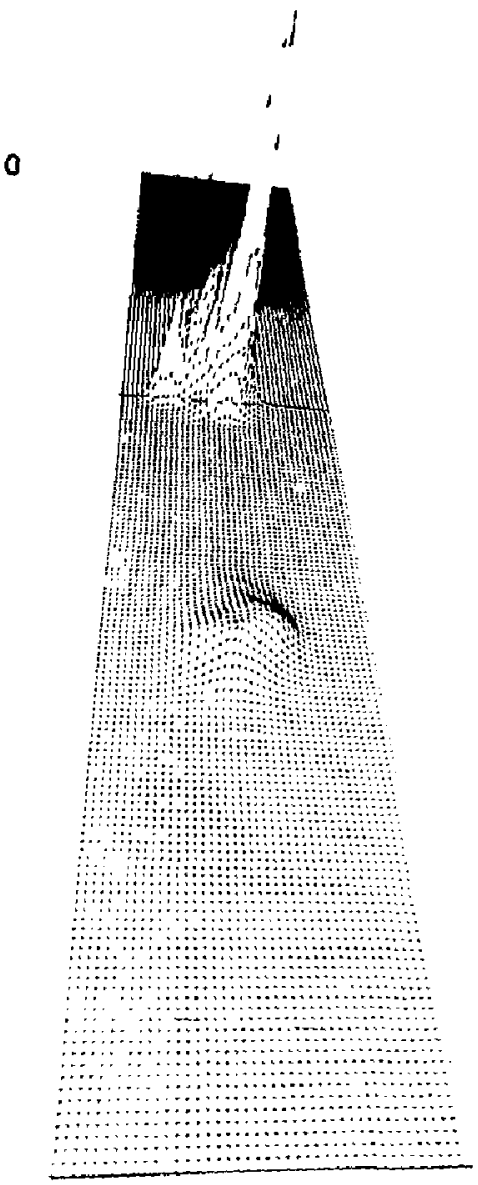

$z$

FIC. 30. Geometric plot ot density gun plasmas.

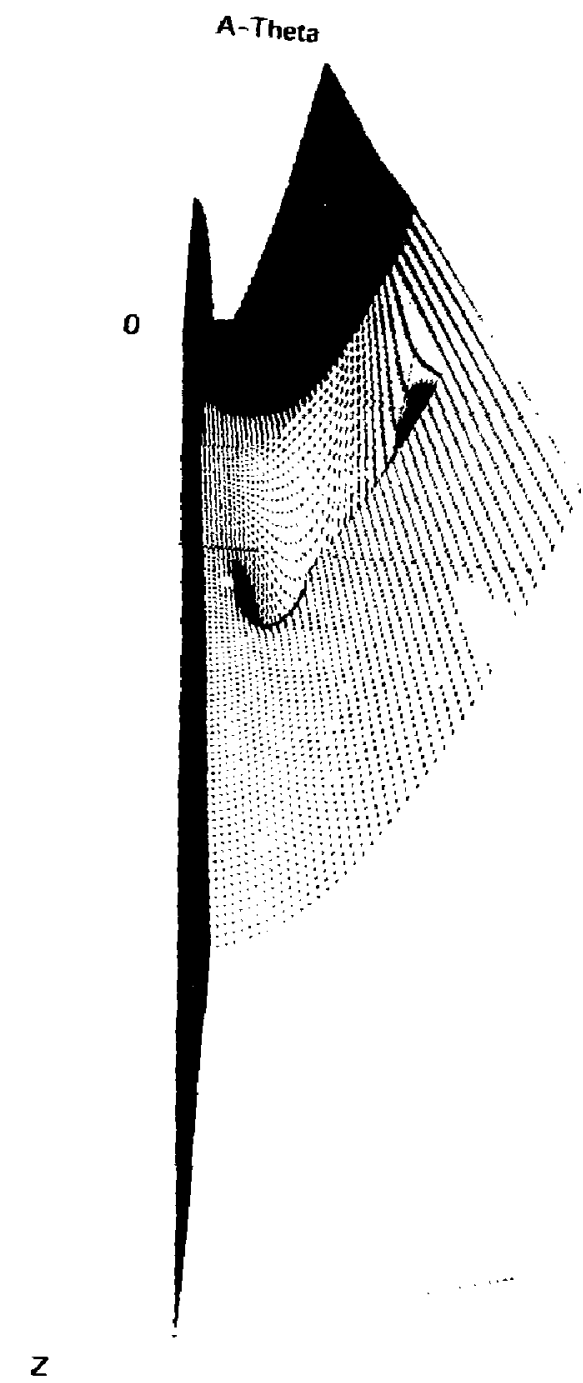

$t=15.9$ Geometric plot of flux at the gin and well formugnetic trench in torus and pinned by the by the compact 
TABLE II. Characteristics of the compact toroid.

\begin{tabular}{|c|c|}
\hline Time & $=19.2$ usecs \\
\hline Toroid thermal energy & $0.602 \mathrm{~kJ}$ \\
\hline Toroid kinetic energy & $0.0252 \mathrm{~kJ}$ \\
\hline Toroid poloidal field energy & $0.369 \mathrm{~kJ}$ \\
\hline Toroid toroidal field energy & $0.0067 \mathrm{~kJ}$ \\
\hline Total energy in coroid & $1.00 \mathrm{~kJ}$ \\
\hline Bank energy supplied & $35.00 \mathrm{~kJ}$ \\
\hline I-Ring current & $-75.6 \mathrm{kA}$ \\
\hline Uensity average & $3.89 \times 10^{14} \mathrm{~cm}^{-3}$ \\
\hline rotal particles & $3.12 \times 10^{19}$ \\
\hline Mean electron temperature & $39.0 \mathrm{eV}$ \\
\hline Mean ion temperature & $41.7 \mathrm{eV}$ \\
\hline Axial velocity at 0 -point & $-1.25 \mathrm{~cm} / \mathrm{usec}$ \\
\hline Field on axis & $-1.05 \mathrm{kG}$ \\
\hline Reversfd $f l u x$ at axis & $-17.2 \times 10^{2} \mathrm{~kg} \mathrm{~cm} \mathrm{~cm}^{2}$ \\
\hline Ring vplume & $80.1 \%$ or $L$ \\
\hline Toroidal fiela at 0 -point & $-706.0 \mathrm{G}$ \\
\hline
\end{tabular}

FINAL REMARKS

This report las described a typical simulation of the BetarII gun experirients. The time and field and density scales agree semi-quantitatively. The main differences are in the temperature, which is dominaceo by impurities, and in the $f l u$, which is enhanced considerably by iuree-dimensional instabilities. Formulae have been developed, based on conservation of helicity, to explain the flux enhancement, and experimencal effort are underway to eliminate the itpurities. Another difference is that the Befa-II experiment still indicates a digh density in the entrance to the tlux conserver after reconnection is complete. The computations also acineve reconnection someshat faster than the experiment. 
Despite these differences, further calculations are underway to simulate high energy, lower-density discharges for neutral injection, and for possible denonstration reactor designs.

REFERENCES

1. S. Maxon and J. Eddleman, "Two-Dimensional Magnetohydrodynamic Calculations of the Plasma Torus," Pinys. Fluids 2l, 1856 (1978).

2. D. V. Anderson, et al., "Theory of Field-Reversed Mirrors and Field-Reversed Plasma-Lun Experiments," in Pruceedings of the 8ch International Conference on Plasma Physics and Controlled Nuclear Fusion (Brussels, 1980) [also a Lawrence Livermore National Laboratory report, Livertmore, CA, UCRL-83518].

3. W. L. Turner, et al., "Formation of Compace Toroidal plasmas by Magnetized Coaxial Plasma Gun Injection into an oblate Flux Conserver," in Proceedings of the lijird Symposium on the Pliysics and Technology of Coupact Toroids (Los Alamos Scientífic Laboratory, Los Alamos, NM, 1980) [also a Lawrence Livermore Nationa] Laboratory report, Livermore, LA, ULRL-85122].

+. H. E. Dalhed, "Cricical bias Fields lar lilting Stability in the Beta-II cxperinent," in Proceedings ot the Third symposium on the physics and dechnology of lompact Loruids (Los Alamos National Scientific Laboratary, Lus Alamos, NM, Lri-b7uUc, 1900).

5. A. S. Sgro, "Calculations or the Eirects of Incomplete Preionizacion in High-Vojtage Theta Pinches," Phys. Fluids 21, 1410 (1978).

o. V. H. Vaseliunas, Kev. Geophys. Space Phys. 13, 303-310 (1975). 